\title{
Inovação na Indústria Brasileira: uma Análise Exploratória a Partir da PINTEC*
}

\author{
Sérgio Kannebley Junior \\ Faculdade de Economia e Administração-Ribeirão Preto/USP \\ Geciane Silveira Porto \\ Faculdade de Economia e Administração-Ribeirão Preto/USP
}

Elaine Toldo Pazello

Instituto de Pesquisas Econômicas/USP

Recebido em 4/12/2003 Aprovado em 22/3/2004

\section{ResUMO}

Este artigo reporta um esforço de caracterização das empresas inovadoras industriais brasileiras. Esta caracterização é realizada com base em informações constantes na PINTEC-2000 (Pesquisa Industrial de Inovação Tecnológica-2000). Para isso foram empregados procedimentos estatísticos não-paramétricos, que informaram, em ordem decrescente, que os quatro principais fatores distintivos entre empresas inovadoras e não-inovadoras são: a orientação exportadora, o tamanho da empresa, a origem estrangeira do capital e a variação interindustrial. Também foi conduzida uma análise econométrica para as informaçōes setoriais, onde foi possível complementar e referendar parte dos resultados obtidos para toda indústria.
PalaVRas-chaVe | Inovação Tecnológica; Redes Neurais; Tópicos Relacionados
Códigos JEL ｜ L2, C45, O31

\footnotetext{
* Este artigo é parte integrante do trabalho "Características das Empresas Inovadoras no Brasil: Uma Análise Empírica a Partir da PINTEC" financiado pela FINEP e realizado no âmbito do Diretório de Pesquisa Privada (DPP). Os autores gostariam de agradecer aos pareceristas anônimos pelos comentários, além dos membros do DPP pelas sugestões e críticas efetuadas nas discussões realizadas sobre esse trabalho nos seus diversos seminários.
} 
AbSTRACT

This article reports an effort to characterize Brazilian innovative firms. This characterization was done based on data from PINTEC-2000 (Industrial Research of Technological Innovation-2000) information. To do it, a statistical non-parametrical procedure was employed, which informed, in a decreasing order, that the four main factors that distinguish innovative and non-innovative firms were the export orientation, the size of the firm, the foreign capital origin, and the industrial sector effect. An econometric analysis of sectorial data was carried out which made possible to complement and endorse the results obtained earlier for the whole industry.

KeYwORDS | Technological Innovation; Neural Networks; Related Topics

JEL-CODES I L2, C45, O31

\section{Introdução}

O objetivo deste trabalho é identificar as características das empresas inovadoras a partir das informações constantes na PINTEC-2000 (Pesquisa Industrial de Inovação Tecnológica realizada pelo IBGE-2000). A partir do universo de 72 mil empresas, com dez ou mais pessoas ocupadas, é conduzida uma extensa análise estatística e econométrica com o objetivo de identificar as características das empresas inovadoras tanto para a indústria, como para os seus respectivos setores CNAE (Classificação Nacional de Atividades Econômicas) a dois dígitos.

A literatura empírica sobre os fatores determinantes das atividades inovativas das empresas encontra-se bastante desenvolvida. As resenhas de Cohen e Levin (1989), Cohen (1995) e Kumar e Siddharthan (1997) apresentam diversos argumentos teóricos e resultados obtidos em testes empíricos sobre este tema para países desenvolvidos e em desenvolvimento. Usualmente a realização de atividades inovativas, ou a intensidade com que são reali- 
zadas, é explicada pelas características das firmas, pelas estruturas de mercados, pela variação interindustrial, pelas condições de apropriabilidade e de demanda. Na literatura empírica nacional alguns trabalhos se propuseram a realizar semelhante tarefa, como são exemplos os artigos de Macedo e Albuquerque (1999), Quadros et al. (2001), Andreassi e Sbragia (2002), Sbragia et al. (2002). Especificamente nesse trabalho, o que se pretendeu realizar, agora para a indústria nacional, foi uma extensão do trabalho realizado por Kannebley (2003) para a indústria paulista.

É importante esclarecer que este trabalho não tem a pretensão de realizar análises que invoquem conhecimentos setoriais específicos, ou que tenham como preocupação fundamental discutir questóes relacionadas à dinâmica tecnológica da indústria, ou especificamente, de seus setores. $\mathrm{O}$ objetivo primordial deste trabalho é apresentar um conjunto de resultados que facilitem a interpretação de estudos setoriais específicos, e de fornecer um ponto de partida para o prosseguimento de estudos baseados na PINTEC.

Para isso o trabalho é composto, além desta seção introdutória, de mais três seçōes. Na primeira são apresentadas a fonte de dados e a estrutura metodológica do trabalho. Metodologicamente, além da análise descritiva das informaçóes da PINTEC, foram estimados modelos de regressão logística e árvores de regressão a fim de explicar a probabilidade de inovação. $\mathrm{Na}$ segunda seção são apresentados os resultados dessas estimações para a indústria geral. Já na terceira são apresentados os resultados das estimações de modelos de regressão logística para os setores industriais. Por fim, na quarta seção são tecidas algumas considerações finais sobre o estudo.

\section{Fonte de dados e metodologia de análise empírica}

\subsection{Fonte de dados e variáveis selecionadas}

A PINTEC é uma pesquisa de âmbito nacional para o período de 1998 a 2000 sobre inovação de processo e produto. A unidade de investigação da PINTEC é a empresa industrial, sendo as atividades produtivas industriais classificadas segundo a CNAE. O universo de pesquisa corresponde a $72.005 \mathrm{em}-$ presas, atuantes no território nacional com dez, ou mais, empregados. Nela 
constam informaçóes concernentes às características das empresas, às atividades tecnológicas empreendidas, seus impactos e fatores que influenciam estas atividades e as empresas como um todo. A principal limitação no uso dessa base de dados deve-se ao fato da pesquisa ser em um único ponto do tempo, isto é, uma cross-section. Isso não permite que sejam capturadas as relações dinâmicas da atividade inovativa postuladas pela teoria econômica. Por outro lado, a grande vantagem que o trabalho com a base expandida fornece é a disponibilização de microdados das empresas industriais brasileiras, que combinem as diversas características das empresas industriais com informações sobre suas atividades inovativas, evitando a produção de resultados enviesados em direção a alguma característica específica das empresas.

Neste trabalho as empresas são qualificadas como inovadoras ou como nãoinovadoras, independentemente da forma de inovação (processo e/ou produto) e do alcance da inovação (para o mercado ou apenas para a empresa). ' Baseado na literatura teórica e empírica sobre o tema, e considerando a disponibilidade de informações sobre as características das empresas na PINTEC, utilizam-se cinco variáveis explicativas que buscam retratar as empresas inovadoras segundo suas características, quais sejam: o tamanho da firma, sua orientação exportadora, origem do capital, estrutura societária e o setor industrial ao qual pertence.

A variável de tamanho da firma é usualmente associada à hipótese schumpeteriana de relação positiva, mas não necessariamente linear ou contínua, entre atividade inovativa e tamanho da firma. Vários argumentos são tecidos para se justificar o efeito positivo do tamanho da firma sobre a atividade inovativa, entre os quais: i) imperfeição do mercado de crédito (grandes firmas teriam mais facilidade para financiar projetos de P\&D de risco visto que tamanho é correlacionado com a disponibilidade e estabilidade de fundos internos para investimento; ii) existência de economias de escala na função de P\&D propriamente dita, considerando que os retornos de P\&D são mais altos quando o inovador tem um maior volume de vendas sobre o qual consegue diluir mais facilmente os custos fixos da inovação, particularmente nos casos de inovação de processo; iii) P\&D é dito ser mais produtivo nas grandes empresas devido à complementaridade entre $P \& D$ e outras atividades não-manufatureiras

A inovação tecnológica é definida na PINTEC pela implementação de produtos (bens ou serviços) ou processos tecnologicamente novos. 
(marketing e planejamento) existente em maior grau nestas empresas; iv) firmas maiores, diversificadas providenciam economias de escopo ou reduzem o risco associado à inovação. ${ }^{2}$

Com relação à orientação exportadora deve-se esperar que a exposição à competição do mercado internacional incentive a firma a investir em atividades inovativas. Isso seria feito no intuito de atender à demanda mais exigente e as pressōes competitivas mais intensas enfrentadas no mercado internacional. Argumenta-se também que as exportações, ao ampliarem os mercados das firmas, aumentam os retornos da atividade inovativa na medida em que diluem seus custos. No entanto, é importante lembrar que essa relação pode estar sujeita a um problema de simultaneidade, na medida em que a atividade tecnológica também pode aprimorar a capacidade competitiva, permitindo que a empresa seja capaz de enfrentar os mercados internacionais mais competitivos. ${ }^{3}$

As empresas multinacionais são detentoras de um conjunto de ativos intangíveis, como marcas internacionalmente reconhecidas, acesso cativo à tecnologia e capacitações gerenciais e organizacionais. Em razão disso é possível que a estratégia competitiva da empresa multinacional em um país local seja uma estratégia de rivalidade não baseada em preços. Essa estratégia de rivalidade não baseada em preços estaria apoiada em gastos em marketing, controle de qualidade e desenvolvimento de produtos, além de um conjunto de serviços ao consumidor. De acordo com esse arcabouço competitivo é possível se conceber uma relação positiva entre a execução de atividades tecnológicas e a natureza estrangeira do capital. Esta relação deve ser mais forte em atividades relacionadas ao desenvolvimento e/ou adaptação de produtos ao mercado doméstico. Em conjunção a essas características, também é passível de ser

\footnotetext{
2 Por outro lado, existem contra-argumentos relacionados à perda de eficiência da atividade de P\&D. Argumenta-se que, quando a firma torna-se muito grande, a eficiência em P\&D é prejudicada em função da perda de controle gerencia ou, alternativamente, devido ao aumento excessivo da burocracia que acaba por desviar dos cientistas a atenção dos empresários. Outro ponto: a diminuição da habilidade dos cientistas e empresários em capturar os benefícios de seus esforços individuais pode também diminuir os incentivos destes na busca da inovação. As evidências empíricas ainda que favoreçam a hipótese schumpeteriana, apresentam resultados ambíguos em razão da definição da variável dependente. Em alguns estudos a variável dependente é o total de gastos em $P \& D$, enquanto que em outros trata-se da intensidade de P\&D, dada pela razão entre o total de gastos de P\&D e o total de vendas da empresa. Adicionalmente, Cohen (1995) relata problemas relacionados ao viés de seleção das amostras, compostas em sua maioria por grandes empresas e inovadoras, e a desconsideração de fatores explicativos específicos à indústria e à empresa.

3 Braga e Willmore (1991) entendem que seja mais provável que a primeira linha de argumentação é a que melhor se adequa ao caso brasileiro em razão do Brasil ser um país em desenvolvimento. Em seu estudo encontram uma relação positiva e estatisticamente significante entre a probabilidade de existência de atividade tecnológica e a orientação exportadora das empresas.
} 
determinante na ocorrência de tais atividades o fato da empresa pertencer a um grupo empresarial, nacional ou estrangeiro. É possível se justificar essa relação em razão do possível acesso a fontes de financiamento internas ao grupo, participação nas estratégias de desenvolvimento do grupo ou ainda a própria identificação dessa característica com a natureza estrangeira do capital da empresa.

Por fim, usualmente verifica-se uma diferença interindustrial no grau em que as indústrias se engajam em atividades inovativas. Os argumentos que tentam explicar essas diferenças estão na maior parte relacionados às diferentes oportunidades de progresso tecnológico que as indústrias percebem. Em termos empíricos, desconsiderar a capacidade explicativa das diferenças interindustriais constitui um problema de viés por omissão de variável relevante. ${ }^{4}$

Todas estas informações estão disponíveis na PINTEC, com exceção daquela relativa à orientação exportadora, que é fornecida pela SECEX (Secretaria de Comércio Exterior). A construção das variáveis empíricas, bem como as transformações utilizadas para a condução das estimações estatísticas, é descrita com mais detalhes no Quadro 1.

\subsection{Metodologia de análise empírica}

Neste trabalho serão empregados dois instrumentos estatísticos para o auxílio na determinação da relação entre o perfil das empresas e suas atividades inovativas, quais sejam: modelos de regressão logística e árvores de classificação e regressão. A seguir, é realizada uma breve discussão sobre os métodos aqui empregados.

\subsubsection{Modelos de regressão logística (modelos Logit)}

Este modelo tem como objetivo final estimar a probabilidade de um determinado evento ocorrer. Assim suponha dois eventos $\mathrm{Y}_{\mathrm{i}}=0$ e $\mathrm{Y}_{\mathrm{i}}=1$, sendo

4 Este problema é freqüentemente encontrado em estudos que procuram analisar as relações entre tamanho, grau de concentração e P\&D, levando a estimativas enviesadas do efeito do tamanho ou da estrutura de mercado sobre a atividade inovativa. Para evitar tal problema neste artigo, conforme será visto adiante, buscar-se-á capturar estes efeitos por meio da categorização dos setores segundo as oportunidades tecnológicas, de acordo com a intensidade do fator de produção, categorias de uso dos bens produzidos ou ainda por meio de variáveis dummies para setores industriais segundo a divisão CNAE a dois dígitos. 
QUADRO 1

Variáveis Utilizadas e suas Transformações

\begin{tabular}{|c|c|}
\hline Variável & Transformações \\
\hline $\begin{array}{l}\text { Não Inova/Inova } \\
\text { (Dependente) }\end{array}$ & $\begin{array}{l}\text { Categórica } \\
0=\text { Não Inova } \\
1=\text { Inova }\end{array}$ \\
\hline $\begin{array}{l}\text { Tamanho da firma } \\
\text { Faixa de pessoal ocupado total na empresa }\end{array}$ & $\begin{array}{l}\text { Categórica } \\
1=10 \text { a } 29 \\
2=30 \text { a } 49 \\
3=50 \text { a } 99 \\
4=100 \text { a } 249 \\
5=250 \text { a } 499 \\
6=500 \text { ou mais }\end{array}$ \\
\hline Pessoal ocupado total na empresa & logaritmo \\
\hline Orientação exportadora SECEX & $\begin{array}{l}\text { Categórica }^{5} \\
0=\text { Não exporta } \\
1=\text { Exporta ocasionalmente } \\
2=\text { Exporta continuamente }\end{array}$ \\
\hline Situação da empresa & $\begin{array}{l}\text { Categórica } \\
1=\text { Independente } \\
2=\text { Controladora } \\
3=\text { Controlada } \\
4=\text { Coligada }\end{array}$ \\
\hline Origem do capital controlador & $\begin{array}{l}\text { Categórica } \\
0=\text { Nacional } \\
1=\text { Estrangeiro } \\
2=\text { Misto }\end{array}$ \\
\hline $\begin{array}{l}\text { Efeitos setoriais } \\
\text { Classificações segundo as oportunidades } \\
\text { Tecnológicas (OPORT1) } 6\end{array}$ & $\begin{array}{l}\text { Categórica } \\
1=\text { Baixa oportunidade } \\
2=\text { Média-baixa oportunidade } \\
3=\text { Média oportunidade } \\
4=\text { Alta oportunidade }\end{array}$ \\
\hline $\begin{array}{l}\text { Intensidade do fator de produção (INTENS) } \\
\text { (Moreira \& Najberg, 1998) }\end{array}$ & $\begin{array}{l}\text { Categórica } \\
1=\text { Intensidade em capital e tecnologia } \\
2=\text { Intensidade em trabalho } \\
3=\text { Intensidade em recursos naturais }\end{array}$ \\
\hline $\begin{array}{l}\text { Categorias de uso (CAT_USO) } \\
\text { (classificação IBGE) }\end{array}$ & $\begin{array}{l}\text { Categórica } \\
1=\text { Bens de capital } \\
2=\text { Bens de consumo duráveis } \\
3=\text { Bens de consumo não-duráveis } \\
4=\text { Bens intermediários }\end{array}$ \\
\hline \multicolumn{2}{|c|}{$\begin{array}{l}5 \text { As empresas classificadas como exportadoras ocasionais são aquelas que exportaram em pelo menos um dos anos entre } \\
1998 \text { e 2000, mas não em todos os anos desse período. Conseqüentemente, aquelas classificadas como exportadoras } \\
\text { contínuas foram aquelas que exportaram em todos os anos entre } 1998 \text { e } 2000 \text {. }\end{array}$} \\
\hline $\begin{array}{l}6 \text { Os setores contidos em cada uma dessas catege } \\
\text { na distribuição empírica da razão entre número } \\
\text { P\&D e o total do pessoal ocupado no setor ind }\end{array}$ & $\begin{array}{l}\text { resentados no Apêndice A. 1. Sua classificação foi construída } \\
\text { s com técnicos de nível superior alocados nas atividades de }\end{array}$ \\
\hline
\end{tabular}


a formulação geral para sua representação probabilista dada por:

$$
\begin{aligned}
& \operatorname{Prob}(Y=1)=F\left(\beta^{\prime} X\right) \\
& \operatorname{Prob}(Y=0)=1-F\left(\beta^{\prime} X\right)
\end{aligned}
$$

em que F é a distribuição cumulativa de probabilidade e o conjunto de parâmetros ß reflete o impacto das mudanças no conjunto de variáveis explicativas $\mathrm{X}$ sobre essa probabilidade. Para que o modelo produza predições consistentes com a teoria subjacente deve-se esperar que:

$$
\begin{aligned}
& \lim _{\beta^{\prime} x \rightarrow+\infty} \operatorname{Prob}(Y=1)=1 \\
& \lim _{\beta^{\prime} x \rightarrow-\infty} \operatorname{Prob}(Y=1)=0
\end{aligned}
$$

Sendo assim, F é representada pela seguinte distribuição logística:

$$
\operatorname{Prob}\left(\mathrm{Y}_{\mathrm{i}}\right)=\mathrm{E}\left(\mathrm{Y}_{\mathrm{i}}\right)=\frac{\mathrm{e}^{\mathrm{z}}}{1+\mathrm{e}^{\mathrm{z}}}
$$

em que:

$Y_{i}$ : variável aleatória discreta igual a 1 se a i-ésima firma realizar uma atividade inovativa específica, e igual a 0 caso contrário;

$$
Z=\beta_{0}+\sum_{j=1}^{J} \beta_{j} X_{i j}
$$

$\mathrm{X}_{\mathrm{ij}}$ : valor da j-ésima variável explicativa para a i-ésima empresa.

$ß_{j}$ é um parâmetro a ser estimado

Os resultados desse modelo são interpretados por meio do cálculo dos efeitos marginais e das razões de chance representadas, respectivamente, pelas seguintes expressões: ${ }^{7}$

$$
\frac{\partial\left(\mathrm{E}\left(\mathrm{Y}_{\mathrm{i}}\right)\right)}{\partial \mathrm{X}_{\mathrm{j}}}=\mathrm{F}\left(\beta^{\prime} \mathrm{X}\right)\left(1-\mathrm{F}\left(\beta^{\prime} \mathrm{X}\right) \beta_{\mathrm{j}}=\mathrm{f}\left(\beta^{\prime} \mathrm{X}\right) \beta_{\mathrm{j}} \text { e } \frac{\operatorname{Prob}\left(\mathrm{Y}_{\mathrm{i}}=1\right)}{\operatorname{Prob}\left(\mathrm{Y}_{\mathrm{i}}=0\right)}=\mathrm{e}^{\mathrm{Z}}\right.
$$

\footnotetext{
As razões de chance podem ser calculadas para o evento inovar considerando-se um valor médio das variáveis explicativas, ou ainda considerando a presença, ou não, de uma característica das empresas expressa pelas variáveis categóricas. A sua interpretação no caso das variáveis contínuas não é clara, sendo recomendável nesse caso o cálculo dos efeitos marginais a partir de valores médios ou medianos das variáveis explicativas. Razões de chance superiores a 1 indicam que existe uma melhora na probabilidade de inovar com a consideração da variável em particular, sendo que o inverso se aplica caso a razão seja inferior a 1 .
} 
As estimações dos modelos são conduzidas inicialmente a partir do modelo geral (considera todas as características das empresas) e passam por um processo de redução baseado na eliminação sucessiva das variáveis não relevantes do modelo (backward stepwise selection). A seleção de variáveis a serem eliminadas é realizada a partir da estimação seqüencial de testes de razão de verossimilhança.

Nas estimações dos modelos o conjunto de variáveis explicativas, conforme apresentado no Quadro 1, segue transformações de modo que estas variáveis assumam valores categóricos. No entanto, para a variável representativa do tamanho da empresa, ao invés de faixas do total de pessoal ocupado é utilizado o logaritmo do total do pessoal ocupado, LnPOTOT. Os efeitos fixos setoriais são captados por variáveis dummies correspondentes a cada setor. ${ }^{8}$

\subsection{2. Árvores de classificação e regressão}

Árvores de classificação são métodos relativamente novos empregados na exploração de relações entre dados em problemas de classificação. Uma árvore de classificação é uma regra para predição da classe de um objeto (variável dependente) a partir dos valores de suas variáveis explicativas. São procedimentos estatísticos não-paramétricos, baseados em algoritmos de busca exaustiva. Os resultados apresentados são estruturas hierarquizadas e flexíveis que permitem a observação de distintas relações entre a variável dependente e diversos subconjuntos de variáveis explicativas. As metodologias mais populares são a CHAID (Chi-Square Automatic Iterated Detection) proposta por Kass (1980), a C\&RT (Classification and Regression Tree), de Breiman et al. (1984) e a QUEST (Quick, Unbiased, Efficient, Statistical Tree) proposta por Loh e Shih (1997).

Nesta análise será empregado o método de estimação QUEST. Essa metodologia permite a partição binária dos nós, evitando a extrema complexidade da análise, possibilita a inserção de custos diferenciados de classificação para as categorias e a realização da redução da árvore (prunning) baseado em uma relação benefício/custo. O diagrama a seguir ilustra uma árvore de partição binária com três níveis de classificação. Ela é composta por nós. Desde

${ }^{8}$ Foi considerado como setor de referência o de Produtos Têxteis (17). 
o nó raiz ao nó final, existem diversos nós que formam os ramos de classificação. O nó raiz contém todas as informações da amostra e representa a variável dependente $Y$, com o número de observações para cada uma das duas categorias (0 e 1 no caso) ou classes. À medida que a árvore se expande, os dados são ramificados em subconjuntos mutuamente exclusivos. Esses subconjuntos são ramos da árvore. No nível seguinte da árvore a amostra é dividida segundo o melhor preditor de $\mathrm{Y}$, a variável explicativa $\mathrm{X}_{1}$. $\mathrm{O}$ nó 1 apresenta o subconjunto de informações de $\mathrm{Y}$, classificado segundo uma regra do tipo $\mathrm{X}_{1}<\mathrm{c}$, enquanto que o nó 2 classifica as informações de $\mathrm{Y}$ segundo a regra $\mathrm{X}_{1}=\mathrm{c}$, em que c é um número ou categoria qualquer correspondente à variável $\mathrm{X}_{1}$. Esses nós $1 \mathrm{e}$ 2 contém informações sobre as freqüências da variável $Y$ relacionadas a cada subgrupo, definido segundo as combinações $\left(\mathrm{Y}, \mathrm{X}_{1}<\mathrm{c}\right)$ e $\left(\mathrm{Y}, \mathrm{X}_{1}=\mathrm{c}\right)$. Os nós 1 e 2 são os pais dos nós 3, 4, 5 e 6. Para o nó 1 o melhor preditor é a variável $\mathrm{X}_{2}$, enquanto que para o nó 2 o melhor preditor é a variável $\mathrm{X}_{3}$. Esses nós filhos, obtidos a partir da divisão segundo os preditores $\mathrm{X}_{2}$ e $\mathrm{X}_{3}$, contém informações sobre as freqüências da variável $Y$ relacionadas a cada subgrupo definido segundo as combinações $\left(\mathrm{Y}, \mathrm{X}_{1}, \mathrm{X}_{2}\right)$ e $\left(\mathrm{Y}, \mathrm{X}_{1}, \mathrm{X}_{3}\right)$. Estes últimos nós, por se encontrarem ao final da árvore, também são chamados de nós terminais. São esses nós que informam o caminho interativo das variáveis explicativas para cada categoria da variável dependente a ser explicada.

A estimação da árvore envolve o estabelecimento de vários parâmetros. Para a determinação da extensão da árvore são estabelecidos pelo pesquisador a extensão máxima de níveis de nós da árvore e as freqüências mínimas nos nós pais e filhos. A classificação ainda é realizada em razão dos custos de má classificação e a probabilidade a priori para as categorias da variável dependente. ${ }^{9}$ Todos esses parâmetros influem nos resultados obtidos pela árvore. Particularmente aqui, é interessante analisar a influência desses dois últimos parâmetros na possibilidade de se trabalhar com classes desequilibradas e custos distintos de má classificação. Conforme será demonstrado adiante a proporção de casos de empresas inovadoras é bastante inferior à proporção de empresas não-ino-

9 As probabilidades a priori, ou "priors", especificam o quanto é provável, sem usar qualquer conhecimento a priori dos valores dos preditores, que um caso ou objeto pertença a uma das classes. No problema de classificação o pesquisador pode estabelecer que as probabilidades a priori sejam iguais às proporções de cada classe da variável dependente, equalizar esses valores para todas as classes, ou ainda estabelecer estes valores segundo uma idéia distinta sobre o fato. Já os custos de má classificação são penalidades numéricas para a classificação de um item em uma categoria ao qual este item não pertence de fato. 


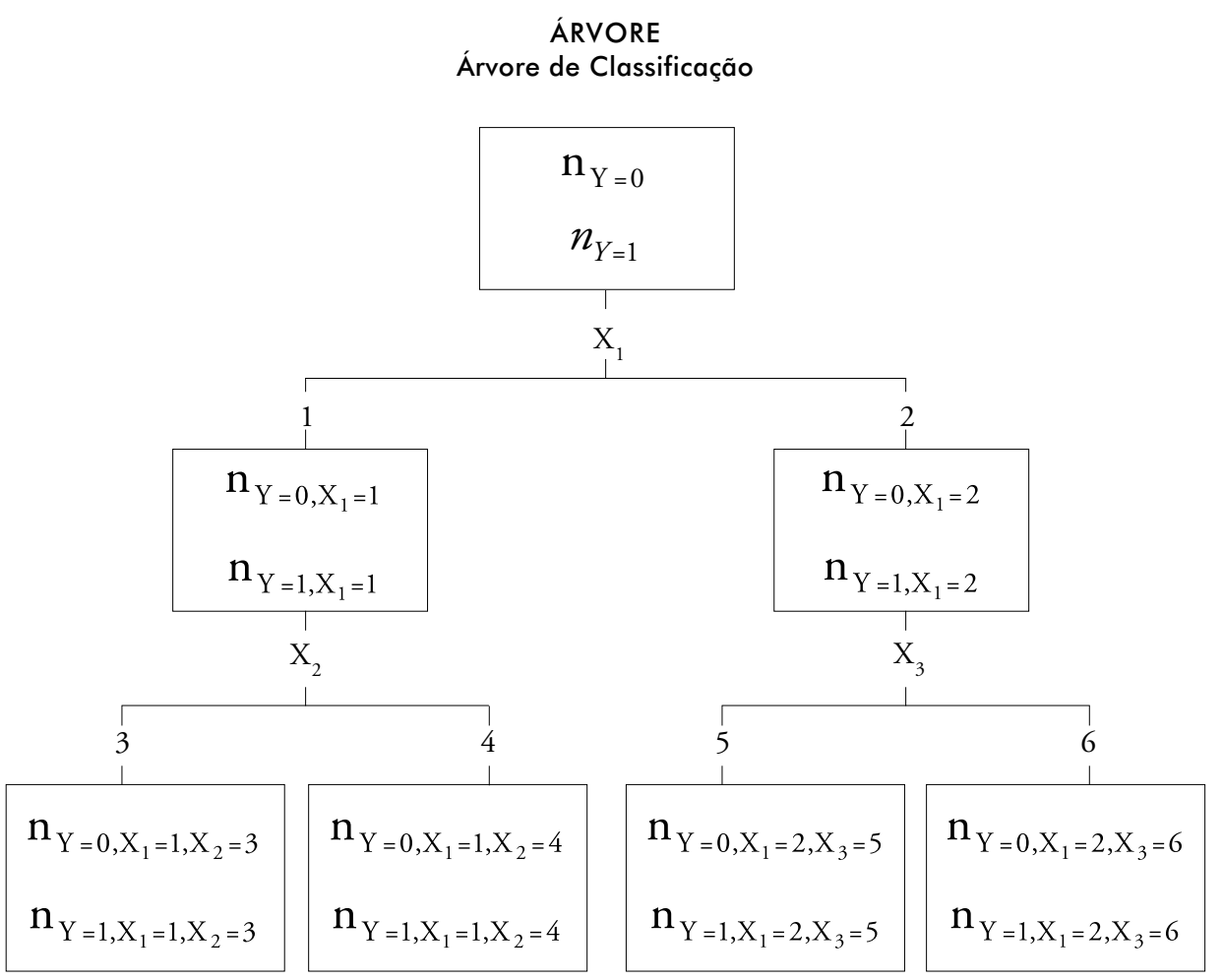

vadoras, produzindo classes desequilibradas. Isso implica que baseado nessas proporções amostrais o algoritmo ajustado para a classificação com custos simétricos para a má classificação, mas com probabilidades a priori baseadas na proporção de casos para cada categoria, deve produzir uma classificação mais acurada para as empresas não-inovadoras. Assim, se é desejado conhecer as características das empresas inovadoras em uma amostra em que predominam as empresas não-inovadoras, isto requer que o custo de má classificação seja superior para a classificação errônea de uma empresa inovadora como nãoinovadora, ou seja, devem ser estabelecidos custos assimétricos de classificação entre os possíveis tipos de erros. É óbvio que o inverso também pode ser feito caso pretenda-se classificar com maior acurácia as empresas não-inovadoras. ${ }^{10}$

\footnotetext{
${ }^{10}$ Essa discussão demonstra a importância do estabelecimento dos custos de má classificação e, conseqüente, ajuste das probabilidades a priori, na determinação da classificação realizada pela árvore, na medida em que o ponto de partição é fundamental na verificação da relação entre a variável a ser predita e a variável preditora. Ao se alterar o ponto de partição, pode-se alterar tanto a definição das variáveis preditivas selecionadas bem como, os resultados de classificação da árvore.
} 
A medida de capacidade, ou acurácia, preditiva de uma árvore é construída com base em uma matriz de classificação dada por:

\begin{tabular}{lll}
\hline & \multicolumn{2}{c}{ Valor Observado } \\
\hline Valor Predito & Classe A & Classe B \\
Classe A & $\mathrm{N}_{A C}$ & $\mathrm{~N}_{A M}$ \\
Classe B & $\mathrm{N}_{B M}$ & $\mathrm{~N}_{B C}$ \\
\hline
\end{tabular}

em que

$\mathrm{N}_{\mathrm{jC}}$ é número de observações corretamente classificadas com $\mathrm{j}=\mathrm{A}, \mathrm{B}$

$\mathrm{N}_{\mathrm{j} M}$ é número de observações incorretamente classificadas com $j=A, B$

$\mathrm{N}_{\mathrm{j}}=\mathrm{N}_{\mathrm{jC}}+\mathrm{N}_{\mathrm{jM}} \operatorname{com} \mathrm{j}=\mathrm{A}, \mathrm{B}$

Essa medida é igual a 1 - Risco, em que o Risco (ou erro aparente) é dado por:

$$
\text { RISCO }=R(T)=\left(\frac{N_{A M}+N_{B M}}{N_{A}+N_{B}}\right) * 100
$$

Neste artigo o risco será calculado utilizando o procedimento de validação cruzada. Esse procedimento determina um número de subamostras aleatórias, de igual tamanho se possível. No presente caso igual a dez amostras. Com isso, a árvore de classificação é computada dez vezes, sendo que em cada uma dessas rodadas, uma dessas subamostras é deixada de fora da amostra e utilizada como amostra de teste para a validação da árvore. $\mathrm{O}$ risco estimado apresentado em (5) será igual à média dos riscos obtidos em cada uma dessas estimaçôes.

A complexidade de análise de árvore de classificação pode ser um fator de custo para o pesquisador. Assim, à medida que a árvore se expande, por um lado produz o benefício de redução do risco, mas por outro lado traz um custo com o aumento de sua complexidade. Um critério de redução da árvore é aquele que considera essa relação benefício/custo. Sendo assim, para a redução da árvore é utilizado um índice custo-complexidade que mede o risco e complexidade da árvore, dado por: 


$$
\mathrm{R}_{\alpha}(\mathrm{T})=\mathrm{R}(\mathrm{T})+\alpha|\widetilde{\mathrm{T}}|
$$

em que $\alpha$ é o custo de complexidade e $|\widetilde{T}|$ é o número de nós terminais para uma árvore T. ${ }^{11}$ O processo de redução é realizado por meio da estimação de uma seqüência de subárvores em que são removidos sub-ramos que promovem a menor redução do risco, relativamente ao cálculo recursivo de uma medida de complexidade. A escolha da árvore reduzida é feita de tal forma que o risco da menor das subárvores seja menor ou igual ao risco da árvore de mínimo risco mais um erro padrão do risco.

\section{Características das empresas inovadoras na indústria geral}

\subsection{Análise descritiva}

Nessa subseção são apresentadas informações relativas às empresas nãoinovadoras e inovadoras. A Tabela 1, apresenta a distribuição dessas classes de firmas por setores industriais, no período de 1998 a 2000. Nessa tabela, os setores foram organizados de forma decrescente, iniciando-se pelo setor que apresentou o maior percentual de empresas que realizou inovação até o setor com a menor concentração de empresas inovadoras. Considerando o percentual médio de $31,5 \%$ do total de empresas inovadoras na amostra, é possível dizer que os principais setores inovadores são: Informática, Eletrônicos Básicos, Comunicações, Médico-Hospitalares e Celulose com taxas de inovação iguais a $68,5 \%, 62,9 \%, 62,1 \%, 59,1 \%$ e $51,8 \%$, respectivamente. Por outro lado, os setores menos inovadores são os de Minerais Não-metálicos, Siderurgia, Extrativo Mineral, Madeira e Reciclagem com 21\%, 19,7\% 17,2\%, 14,3\%, $13,1 \%$, respectivamente.

$\mathrm{Na}$ Tabela 2, as empresas foram classificadas segundo os critérios de faixa de tamanho, origem do capital, orientação exportadora e estrutura societária. As informações foram discriminadas de acordo com o fato das empresas terem realizado, ou não, inovação no período de 1998 a 2000.

\footnotetext{
11 Uma árvore poderia crescer até o momento em que cada nó terminal contivesse somente uma informação. Essa árvore teria um risco mínimo. Isto ocorreria se $\alpha$ fosse igual a zero e T fosse suficientemente grande, combinado à ausência de restrições para as freqüências nos nós pais e filhos. Assim, à medida que $\alpha$ aumenta, a partir de zero, produz-se uma seqüência de subárvores $T_{1}, T_{2}, T_{3}$ com progressivamente um número menor de nós.
} 
Sérgio Kannebley Junior, Geciane Silveira Porto, Elaine Toldo Pazello

TABELA 1

Empresas Classificadas Segundo os Setores CNAE

\begin{tabular}{|c|c|c|c|c|c|}
\hline \multirow{2}{*}{ Setores } & \multicolumn{2}{|c|}{ Não Inova } & \multicolumn{2}{|c|}{ Inova } & \multirow[t]{2}{*}{ Total } \\
\hline & número & $\%$ & número & $\%$ & \\
\hline Informática & 50 & 31,5 & 109 & 68,5 & 159 \\
\hline Eletrônicos Básicos & 90 & 37,1 & 153 & 62,9 & 244 \\
\hline Comunicações & 113 & 37,9 & 185 & 62,1 & 298 \\
\hline Médico-Hospitalares & 288 & 40,9 & 416 & 59,1 & 704 \\
\hline Celulose & 10 & 48,2 & 11 & 51,8 & 22 \\
\hline Materiais Elétricos & 752 & 51,8 & 699 & 48,2 & 1.451 \\
\hline Farmacêutico & 284 & 53,2 & 250 & 46,8 & 535 \\
\hline Peças e Acessórios & 481 & 53,8 & 412 & 46,2 & 894 \\
\hline Químico & 1.343 & 54,0 & 1.143 & 46,0 & 2.486 \\
\hline Máquinas e Equipamentos & 2.180 & 55,6 & 1.744 & 44,4 & 3.924 \\
\hline Outros Equipamentos de Transportes & 225 & 56,3 & 175 & 43,7 & 400 \\
\hline Borracha e Plástico & 2.545 & 60,3 & 1.678 & 39,7 & 4.224 \\
\hline Refino de Petróleo & 27 & 60,6 & 18 & 39,4 & 45 \\
\hline Metalurgia & 571 & 63,8 & 324 & 36,2 & 895 \\
\hline Móveis & 2.780 & 63,8 & 1.577 & 36,2 & 4.357 \\
\hline Fumo & 34 & 65,2 & 18 & 34,8 & 52 \\
\hline Couro e Calçados & 2.194 & 66,4 & 1.112 & 33,6 & 3.306 \\
\hline Edição e Impressão & 2.242 & 66,9 & 1.109 & 33,1 & 3.351 \\
\hline Bebidas & 511 & 67,1 & 251 & 32,9 & 763 \\
\hline Produtos de Metal & 3.878 & 67,2 & 1.889 & 32,8 & 5.767 \\
\hline Têxtil & 1.923 & 68,1 & 900 & 31,9 & 2.824 \\
\hline Fabricação de Combustíveis & 101 & 68,1 & 47 & 31,9 & 149 \\
\hline Diversos & 1.196 & 70,0 & 512 & 30,0 & 1.708 \\
\hline Alimentos & 6.717 & 70,8 & 2.773 & 29,2 & 9.491 \\
\hline Montagem de Veículos & 632 & 73,7 & 226 & 26,3 & 858 \\
\hline Vestuário e Acessórios & 6.568 & 73,8 & 2.334 & 26,2 & 8.902 \\
\hline Papel & 1.004 & 75,6 & 323 & 24,4 & 1.328 \\
\hline Minerais Não-Metálicos & 4.747 & 79,0 & 1.262 & 21,0 & 6.009 \\
\hline Siderurgia & 291 & 80,3 & 71 & 19,7 & 363 \\
\hline Extrativo Mineral & 1.432 & 82,8 & 297 & 17,2 & 1.729 \\
\hline Madeira & 3.988 & 85,7 & 664 & 14,3 & 4.652 \\
\hline Reciclagem & 109 & 86,9 & 16 & 13,1 & 126 \\
\hline
\end{tabular}

IOO Revista Brasileira de Inovação 
A distribuição por tamanho indica que $65,4 \%$ das empresas estão na categoria de microempresas, $23,7 \%$ na de pequenas empresas, $9 \%$ na de médias empresas e $1,9 \%$ na de grandes empresas. ${ }^{12}$ É notória a relação positiva entre o tamanho e a ocorrência de inovação. Como é possível observar, entre as microempresas, apenas $25,3 \%$ delas inovaram no período, enquanto que entre as grandes empresas, esse percentual atinge 75,6\%.

No que diz respeito à origem do capital, $97,1 \%$ das empresas são constituídas por capital nacional, 2,3\% por capital estrangeiro e $0,6 \%$ por capital misto. Sendo assim, ainda que em termos absolutos, as empresas nacionais tenham sido mais inovadoras, em termos percentuais, ocupam a última posição nessa classificação. Proporcionalmente, predominam as empresas inovadoras de capital estrangeiro (65,9\%), seguidas das empresas inovadoras de capital misto $(54,8 \%)$. A taxa de inovação para as empresas de capital nacional é de apenas 30,6\%.

Quando analisadas segundo à orientação exportadora, observa-se que no período em questão, $83,5 \%$ das empresas não exportaram, 7,4\% exportaram ocasionalmente e 9,2\% exportaram continuamente. Entre as empresas que exportaram ocasionalmente e continuamente são encontrados os maiores percentuais de empresas inovadoras, $46,7 \%$ e $57,9 \%$, respectivamente, contra apenas $27,3 \%$ das empresas inovadoras e não-exportadoras.

Por fim, com relação à estrutura societária, dado que a grande maioria das empresas é independente (96,4\%), isto é, não fazem parte de um grupo de empresas, esta categoria abrigou o maior número de empresas inovadoras e não-inovadoras. No entanto, em termos percentuais, somente $30,5 \%$ das empresas independentes realizaram inovaçôes no período, enquanto que $60,3 \%$ das empresas controladoras de grupos, 58,7\% das empresas controladas e 53,7\% das empresas coligadas realizaram inovações no mesmo período.

$\mathrm{Na}$ Tabela 3, as empresas foram classificadas setorialmente segundo a intensidade do fator produtivo, o grau de oportunidade tecnológica e segundo a categoria de uso do bem produzido. Mais uma vez, os dados foram discriminados de acordo com o fato das empresas terem ou não inovado. Quanto à intensidade do fator produtivo, percebe-se que as empresas encontram-se

\footnotetext{
12 São classificadas como microempresas aquelas empresas com até 19 empregados, as pequenas empresas aquelas com 20 a 99 empregados, médias empresas com 100 a 499 empregados e grandes empresas, aquelas com 500 ou mais empregados.
} 
TABELA 2

Empresas Classificadas Segundo suas Características de Análise

\begin{tabular}{lrrrrrrr}
\hline & \multicolumn{2}{c}{ Não Inova } & \multicolumn{2}{c}{ Inova } & \multicolumn{2}{c}{ Total } \\
& número & $\%$ & número & $\%$ & número & $\%$ \\
\hline Faixa de tamanho & & & & & & & \\
Micro & 35.173 & 74,7 & 11.909 & 25,3 & 47.082 & 65,4 \\
Pequena & 10.656 & 62,4 & 6.430 & 37,6 & 17.086 & 23,7 \\
Média & 3.147 & 48,6 & 3.329 & 51,4 & 6.476 & 9,0 \\
Grande & 332 & 24,4 & 1.029 & 75,6 & 1.361 & 1,9
\end{tabular}

\section{Origem do capital}

$\begin{array}{lrrrrrr}\text { Nacional } & 48.537 & 69,4 & 21.353 & 30,6 & 69.890 & 97,1 \\ \text { Estrangeiro } & 569 & 34,1 & 1.100 & 65,9 & 1.669 & 2,3 \\ \text { Misto } & 201 & 45,2 & 244 & 54,8 & 445 & 0,6\end{array}$

Orientação exportadora

$\begin{array}{lrrrrrr}\text { Não Exporta } & 43.709 & 72,7 & 16.407 & 27,3 & 60.116 & 83,5 \\ \text { Exportações ocasionais } & 2.825 & 53,3 & 2.473 & 46,7 & 5.298 & 7,4 \\ \text { Exportações contínuas } & 2.773 & 42,1 & 3.818 & 57,9 & 6.591 & 9,2 \\ & & & & & & \\ \text { Estrutura societária } & & & & & & \\ \text { Independente } & 48.198 & 69,5 & 21.178 & 30,5 & 69.376 & 96,4 \\ \text { Controladora } & 167 & 39,7 & 254 & 60,3 & 421 & 0,6 \\ \text { Controlada } & 663 & 41,3 & 942 & 58,7 & 1.605 & 2,2 \\ \text { Coligada } & 279 & 46,3 & 323 & 53,7 & 602 & 0,8 \\ & & & & & 72.004 & 100,0 \\ \text { Total de empresas } & 49.307 & 68,5 & 22.697 & 31,5 & & \end{array}$

distribuídas de maneira aproximadamente uniforme, isto é, 31,7\% delas são intensivas em recursos naturais, 31,9\% são intensivas em trabalho e 36,4\% em capital. Entretanto, quanto ao fato de inovar, pode-se notar que as empresas intensivas em capital tendem a ser mais inovadoras: $39,8 \%$ destas são inovadoras, contra $23,1 \%$ e $30,4 \%$ das empresas intensivas em recursos naturais e 
TABELA 3

Empresas Classificadas Segundo as Classificações Setoriais

\begin{tabular}{lccccccc}
\hline & \multicolumn{2}{c}{ Não Inova } & \multicolumn{2}{c}{ Inova } & \multicolumn{2}{c}{ Total } \\
& número & $\%$ & número & $\%$ & número & $\%$ \\
\hline Intensidade & & & & & & & \\
Recursos Naturais & 17.538 & 76,9 & 5.281 & 23,1 & 22.819 & 31,7 \\
Trabalho & 15.994 & 69,6 & 6.977 & 30,4 & 22.971 & 31,9 \\
Capital & 15.775 & 60,2 & 10.439 & 39,8 & 26.214 & 36,4
\end{tabular}

Oportunidade tecnológica

$\begin{array}{lrrrrrr}\text { Baixa } & 43.021 & 71,1 & 17.499 & 28,9 & 60.520 & 84,0 \\ \text { Média-Baixa } & 4.978 & 54,9 & 4.089 & 45,1 & 9.067 & 12,6 \\ \text { Média } & 1.033 & 55,6 & 826 & 44,4 & 1.859 & 2,6 \\ \text { Alta } & 276 & 49,4 & 283 & 50,6 & 559 & 0,8\end{array}$

Uso do bem

Capital

Consumo durável

Consumo não-durável

7.485

58,9

5.216

$2.701 \quad 17,6$

$4.608 \quad 66,6$

$2.314 \quad 33,4$

$6.922 \quad 9,6$

Intermediários

$20.501 \quad 70,1$

$8.765 \quad 29,9$

$29.266 \quad 40,6$

$16.714 \quad 72,3$

$6.403 \quad 27,7$

$23.117 \quad 32,1$

Total de empresas

trabalho, respectivamente. Quando classificadas segundo o grau de oportunidade tecnológica dos setores, verifica-se que as empresas de baixa oportunidade tecnológica são, em geral, menos inovadoras (apenas 28,9\% delas inovaram), enquanto que, conforme esperado, as de alta oportunidade tendem a ser as mais inovadoras (50,6\% do total de empresas). ${ }^{13}$ As taxas de inovação nas categorias média-baixa e média oportunidades tecnológicas são muito próximas $(45,1 \%$ e $44,4 \%$ respectivamente). No tocante à categoria de uso do bem, a maioria das empresas encontra-se nas categorias "consumo não-durável" e

${ }^{13}$ Cabe destacar que, por construção, o número de empresas é sensivelmente menor nas categorias referentes a oportunidades mais altas, já que estas abrigam um menor número de setores e conseqüentemente um menor número de empresas. 
"intermediários" (40,6\% e 32,1\% do total respectivamente). Já as empresas inovadoras distribuem-se percentualmente de modo uniforme, exceto na categoria "bens de capital", onde a proporção de empresas inovadoras é maior do que nas demais categorias ( $41,1 \%$ das empresas são inovadoras).

Dessa forma o que é possível concluir a partir dessa análise descritiva é que as empresas não-inovadoras podem ser "estilizadas" como micro ou pequenas, de capital nacional, não-exportadoras e independentes de grupos empresariais. Todas as características consideradas na análise aparentemente também contribuem para a definição de tipologias de empresas inovadoras. Mas com relação à empresa inovadora, esta estilização não é tão simples de ser realizada. Todas as variáveis consideradas são importantes na definição das características das empresas inovadoras, mas em muitos casos esta definição deve depender da interação entre as características consideradas. Algumas caracterizaçôes parecem mais evidentes e estão relacionadas ao maior tamanho das empresas, à origem estrangeira do capital, ao fato de pertencerem a grupos industriais e de serem exportadoras contínuas ou ocasionais.

\subsection{Modelos de regressão logística}

A estimação de um modelo de regressão logística (logit) para a probabilidade de inovar é realizada a fim de se captar numericamente a influência líquida de cada uma das características das empresas sobre a probabilidade de uma empresa industrial inovar.

Os resultados obtidos para a regressão do modelo logit da probabilidade de inovar para a indústria geral são apresentados na Tabela 4. As estatísticas de razão de verossimilhança (LR) rejeitam a hipótese nula de que todos os coeficientes de inclinação sejam iguais a zero em um nível de significância de $1 \%$. A qualidade do ajustamento dos modelos pode ser observada nas classificações baseadas na probabilidade esperada e pelas estatísticas de $R^{2}$ de Cox \& Sneel e de $R^{2}$ de Nagelkerk, que indicam que as variáveis selecionadas produzem uma melhora na predição da probabilidade da empresa ser inovadora. A porcentagem de acerto do modelo $^{14}$ é de $71 \%$, superior tanto à aposta ingênua de que

${ }^{14}$ A porcentagem de acerto do modelo é o resultado da seguinte equação: $\left\{\left[\%\right.\right.$ de firmas inovadoras] ${ }^{*}[\%$ de acerto de inovadoras $]\}+\{[\%$ de firmas não-inovadoras $] *$ [\% de acerto de não-inovadoras $]\}$. 
TABELA 4

Impacto das Características das Empresas sobre a Probabilidade de a Empresa ser Inovadora - Indústria Geral

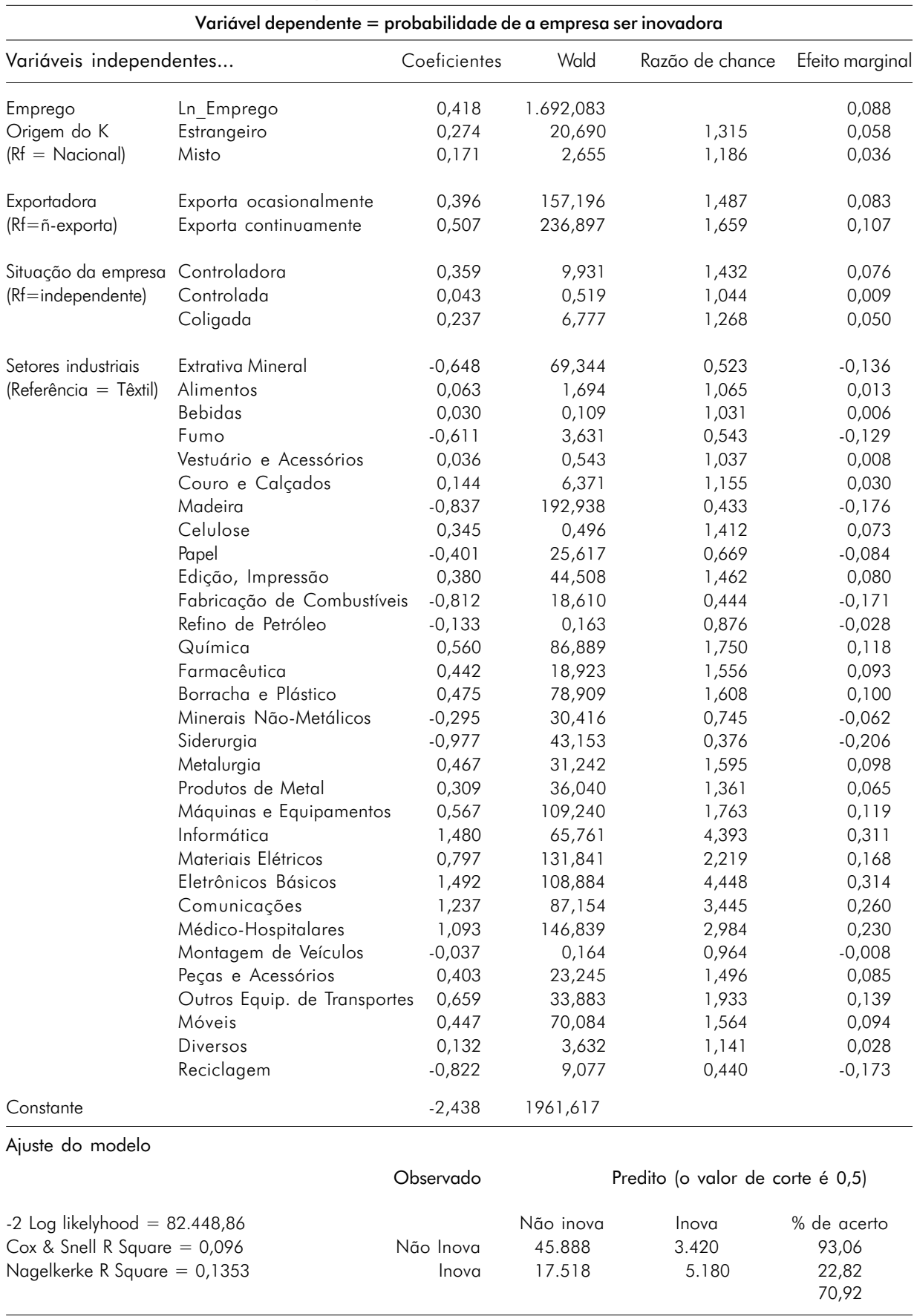


$50 \%$ das firmas inovam quanto à aposta racional de que 68,5\% das empresas são não-inovadoras. Em se tratando das firmas inovadoras, dos 22.698 casos observados, o modelo consegue acertar 5.180, ou seja, 23\%.

Dentre as variáveis do modelo, a orientação exportadora contínua, em primeiro lugar, seguida do tamanho, e a orientação exportadora ocasional são as três principais características explicativas da probabilidade da empresa inovar. Analisando as razões de chance, observa-se que a probabilidade de inovar é 66\% maior para firmas que exportam continuamente comparativamente às firmas não-exportadoras. Este valor cai para $49 \%$ no caso das firmas que exportam ocasionalmente. No caso do tamanho, um aumento de uma unidade nesta variável (logaritmo do pessoal ocupado), aumenta em 8,8 pontos percentuais a probabilidade da empresa inovar (neste caso, olha-se para o efeito marginal, visto que a variável de tamanho é contínua).

A origem estrangeira ou mista do capital (relativamente a ter capital nacional) e o fato de a empresa pertencer a algum grupo empresarial (relativamente a ser independente) também são características que implicam em uma maior probabilidade de a empresa ser inovadora. É importante destacar que, com relação à empresa de capital nacional, a probabilidade de uma empresa de capital estrangeiro ser inovadora é quase o dobro da probabilidade de uma empresa de capital misto ser inovadora, conforme é indicado pelas razões de chance para essas variáveis. Já se a empresa é a "controlada" dentro do grupo empresarial, os resultados não são estatisticamente significativos, ou seja, não há diferença na probabilidade de inovar entre estas e as empresas independentes. É interessante notar que os sinais obtidos estão de acordo com o esperado pela teoria econômica.

As variáveis dummies setoriais refletem a probabilidade de inovação do setor, condicional às características de suas empresas, com relação à probabilidade de inovar do setor de referência (no caso, o setor Têxtil). ${ }^{15}$ De acordo com o modelo estimado, os cinco principais setores inovadores são os de Eletrônicos Básicos, Informática, Comunicações, Médico-Hospitalares e Siderurgia. Na outra ponta, os cinco setores em que a inovação mostra-se menos freqüente são os de Reciclagem, Fabricação de Combustíveis, Extrativa Mineral, Fumo e Papel. ${ }^{16}$

\footnotetext{
15 O setor Têxtil foi adotado como referência por apresentar um indicador de inovação próximo à média da indústria.

${ }^{16}$ A ordenação dos setores é obtida diretamente pela ordenação das razões de chance das dummies setoriais. 
TABELA 5

Sumário Estatístico da Árvore de Risco Mínimo - Custo Simétrico

\begin{tabular}{|c|c|c|c|c|c|c|}
\hline Nós & Freqüência & Percentual & Lucro & \multicolumn{3}{|c|}{ Matriz de Classificação } \\
\hline 9 & 937 & 1,3 & 0,75 & & \multicolumn{2}{|c|}{ Valor Observado } \\
\hline 20 & 1.557 & 2,2 & 0,67 & Valor Predito & Não Inova & Inova \\
\hline 18 & 1.327 & 1,9 & 0,62 & Não Inova & 45.641 & 17.338 \\
\hline 29 & 973 & 1,4 & 0,56 & Inova & 3.473 & 5.031 \\
\hline 28 & 950 & 1,3 & 0,53 & & & \\
\hline 31 & 838 & 1,2 & 0,52 & Risco & 0,291132 & \\
\hline 25 & 729 & 1,0 & 0,51 & & & \\
\hline 14 & 416 & 0,6 & 0,51 & & & \\
\hline 24 & 777 & 1,1 & 0,51 & & & \\
\hline 30 & 919 & 1,3 & 0,45 & & & \\
\hline 16 & 2.622 & 3,7 & 0,45 & & & \\
\hline 13 & 2.532 & 3,5 & 0,44 & & & \\
\hline 23 & 4.483 & 6,3 & 0,36 & & & \\
\hline 27 & 131 & 0,2 & 0,35 & & & \\
\hline 26 & 1.372 & 1,9 & 0,28 & & & \\
\hline 21 & 50.195 & 70,2 & 0,25 & & & \\
\hline 32 & 725 & 1,0 & 0,19 & & & \\
\hline
\end{tabular}

\section{3. Árvores de classificação e regressão}

As interações entre as características das empresas classificadas como inovadoras ou não-inovadoras podem ser observadas mais claramente pela estimação de árvores de classificação e regressão.

As Tabelas 5 e 6 apresentam os sumários estatísticos das Árvores 1 e 2. Essas árvores possuem custos simétricos de classificação, sendo a primeira de risco mínimo e a segunda reduzida de acordo com o critério de custo-complexidade. Como é possível perceber o risco estimado para essas árvores é igual a $0,29 .{ }^{17} \mathrm{Os}$ nós terminais, em ordem decrescente, com maior percentual de empresas inova-

17 Essa estimativa de erro é inferior à estimativa ingênua de 0,5 e também ligeiramente inferior à estimativa de que todas as empresas são não-inovadoras. 
TABELA 6

Sumário Estatístico da Árvore Podada - Custo Simétrico

\begin{tabular}{|c|c|c|c|c|c|c|}
\hline Nós & Freqüência & Percentual & Lucro & \multicolumn{3}{|c|}{ Matriz de Classificação } \\
\hline 7 & 937 & 1,3 & 0,91 & \multicolumn{3}{|c|}{ Valor Observado } \\
\hline 10 & 1.557 & 2,2 & 0,73 & Valor Predito & Não Inova & Inova \\
\hline & & & & Não Inova & 46.904 & 18.704 \\
\hline 6 & 2.408 & 3,4 & 0,63 & Inova & 2.210 & 3.665 \\
\hline 11 & 973 & 1,4 & 0,57 & \multirow[b]{2}{*}{ Risco } & \multirow{3}{*}{$0,292.573$} & \\
\hline 12 & 919 & 1,3 & 0,55 & & & \\
\hline 5 & 4.723 & 6,6 & 0,45 & & & \\
\hline 2 & 59.966 & 83,9 & 0,30 & & & \\
\hline
\end{tabular}

doras são indicados pela coluna lucro nessas tabelas. ${ }^{18} \mathrm{O}$ primeiro nó com maior percentual de empresas inovadoras corresponde à categoria de empresas exportadoras, com 100 ou mais empregados, com capital de origem estrangeira ou mista. O segundo nó é aquele correspondente a empresas exportadoras, com 250 ou mais empregados de capital nacional. O terceiro nó com maior percentual é aquele de empresas exportadoras com mais de 19 e menos de 100 empregados (faixa de pequenas empresas), pertencentes a setores com grau de oportunidade tecnológica média-baixa, média e alta. $\mathrm{O}$ quarto nó em termos percentuais da presença de empresas inovadoras é aquele correspondente às empresas exportadoras nacionais, com menos de 250 empregados, pertencentes a setores intensivos em capital e tecnologia.

Por outro lado, analisando os últimos nós em termos de poder de classificação é possível se obter informações sobre as características das empresas não-inovadoras. Essas empresas estão representadas pelos nós correspondentes

18 É importante esclarecer que a árvore teria como objetivo a classificação estrita em cada nó. Ou seja, todas as informações, em cada um dos nós, deveriam ser de apenas uma das classes (não-inovadora ou inovadora). Sendo assim, se, por exemplo, um nó da árvore contém um percentual da classe inovadora superior a $50 \%$ esse nó está dizendo que mais provavelmente sob aquela partição esse nó representaria a classe de empresas inovadoras segundo classificação proposta pelo ramo ao qual este nó pertence. Dessa forma, a medida de risco do nó é a quantidade complementar ao percentual de empresas inovadoras no nó. É nesse sentido que a tabela de lucros indica os nós em que o grau de homogeneidade é maior, significando que nesses nós a classificação é mais clara, e, portanto, menos sujeita a riscos. 
a empresas não-exportadoras, com menos de 50 empregados pertencentes a setores de baixa ou média-baixa oportunidades tecnológicas, ou ainda aquelas empresas não-exportadoras com 50 a 99 empregados pertencentes a setores não produtores de bens de capital (isto ficará mais claro na Árvore 2.3 que explora as características não-inovadoras). Também é interessante destacar a presença de um nó não-inovador no ramo de empresas exportadoras, correspondentes às empresas atuantes em setores intensivos em recursos naturais, ou em trabalho, com 19 ou menos empregados.

A combinação da análise das Árvores 1 e 2 demonstra que, em termos hierárquicos, a principal variável classificadora das empresas segundo as classes de inovadora e não-inovadora é o fato dessas empresas serem ou não-exportadoras, seguido pelo tamanho das empresas. Posteriormente a isso são também importantes os efeitos setoriais e a origem do capital. Essas informaçôes estão sintetizadas, principalmente, na árvore podada, já que a mesma demonstra o reduzido poder classificador das variáveis utilizadas para classificar as empresas inovadoras nos nós filhos do ramo das empresas não-exportadoras.

ÁRVORE 1

Risco Mínimo com Custos Simétricos

INOVA1

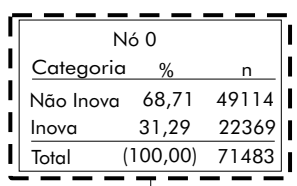

Iotal $\quad(100,00) \quad 71483$ |

EXPORT_1

Adj. - -value $=0,0000$, Chi-square $=2982,0371, \mathrm{df}=2$

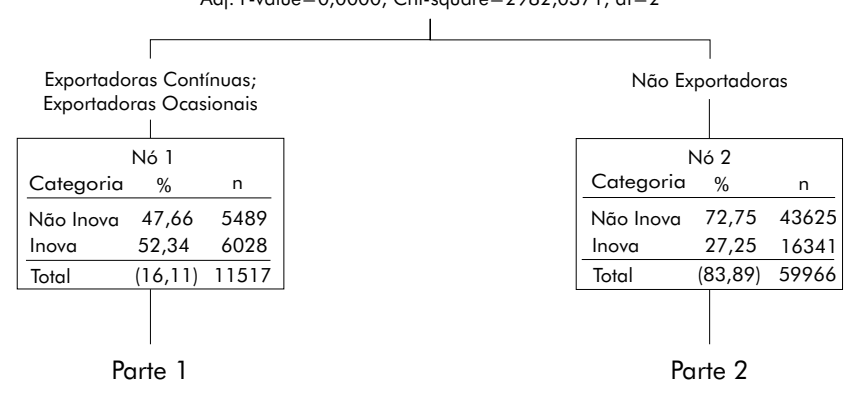


ÁRVORE 1 - parte 1

Risco Mínimo com Custos Simétricos

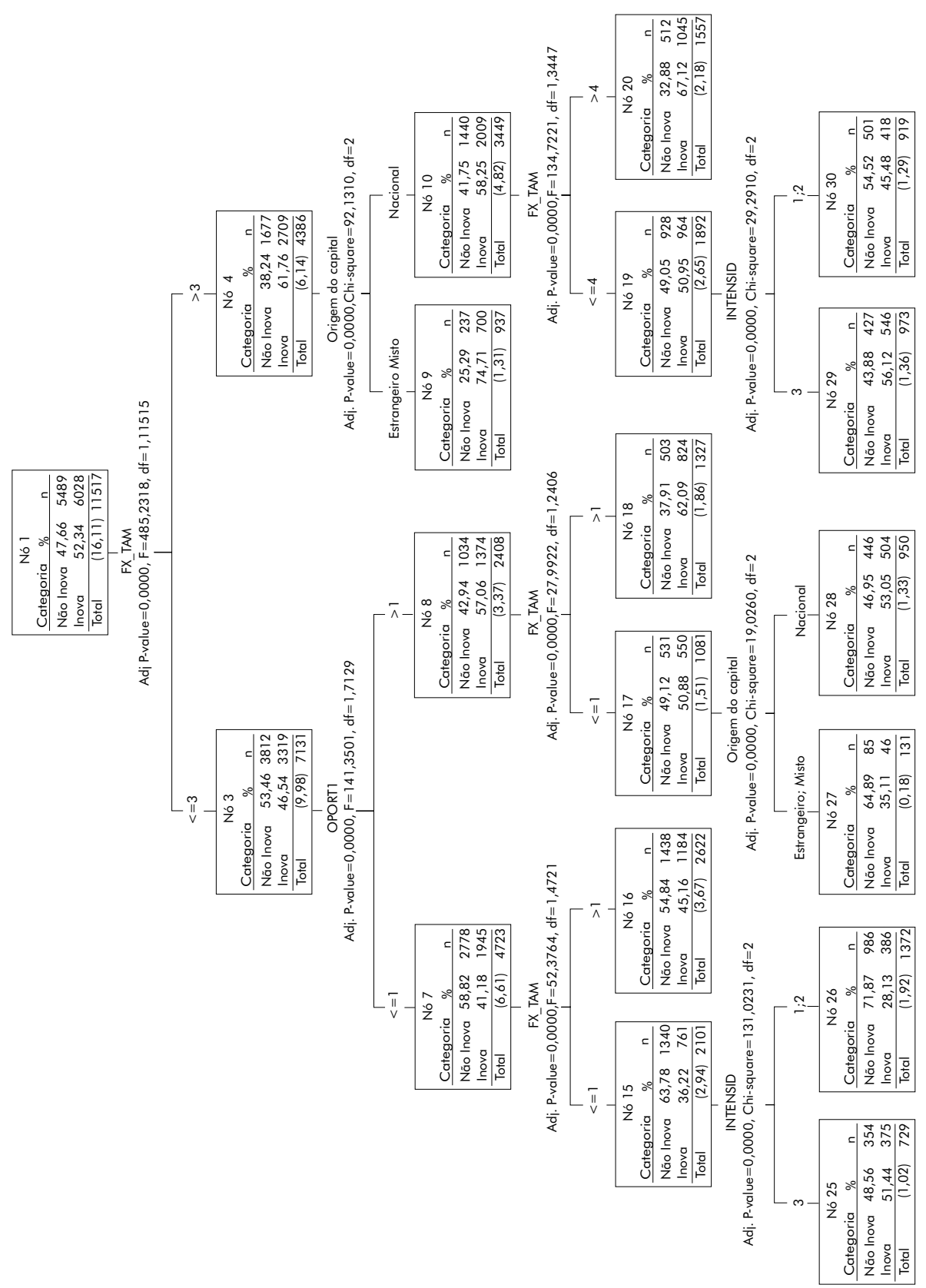

IIO Revista Brasileira de Inovação 
ÁRVORE 1 - parte 2

Risco Mínimo com Custos Simétricos

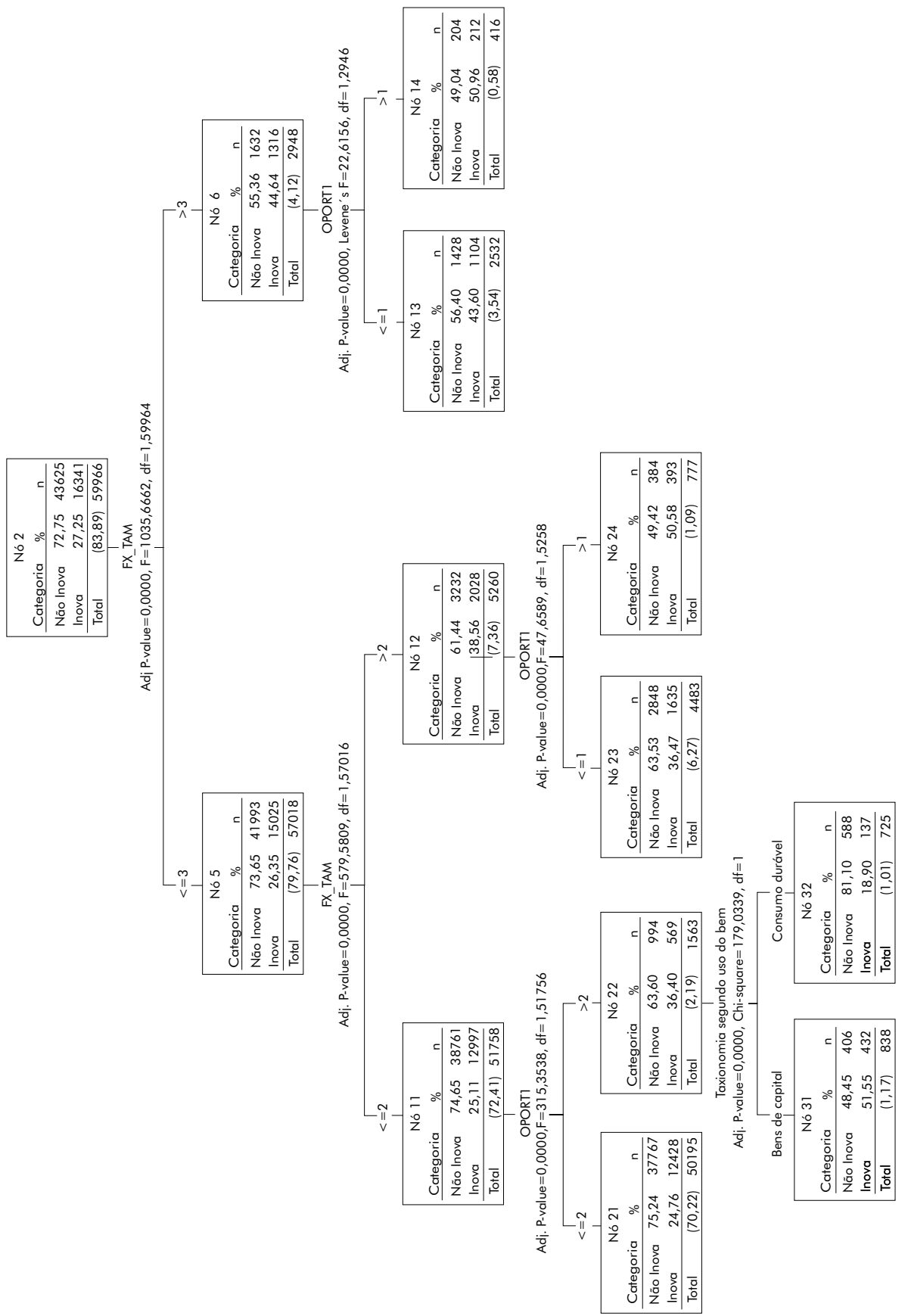


Sérgio Kannebley Junior, Geciane Silveira Porto, Elaine Toldo Pazello

\section{ÁRVORE 2}

Podada com Custos Simétricos

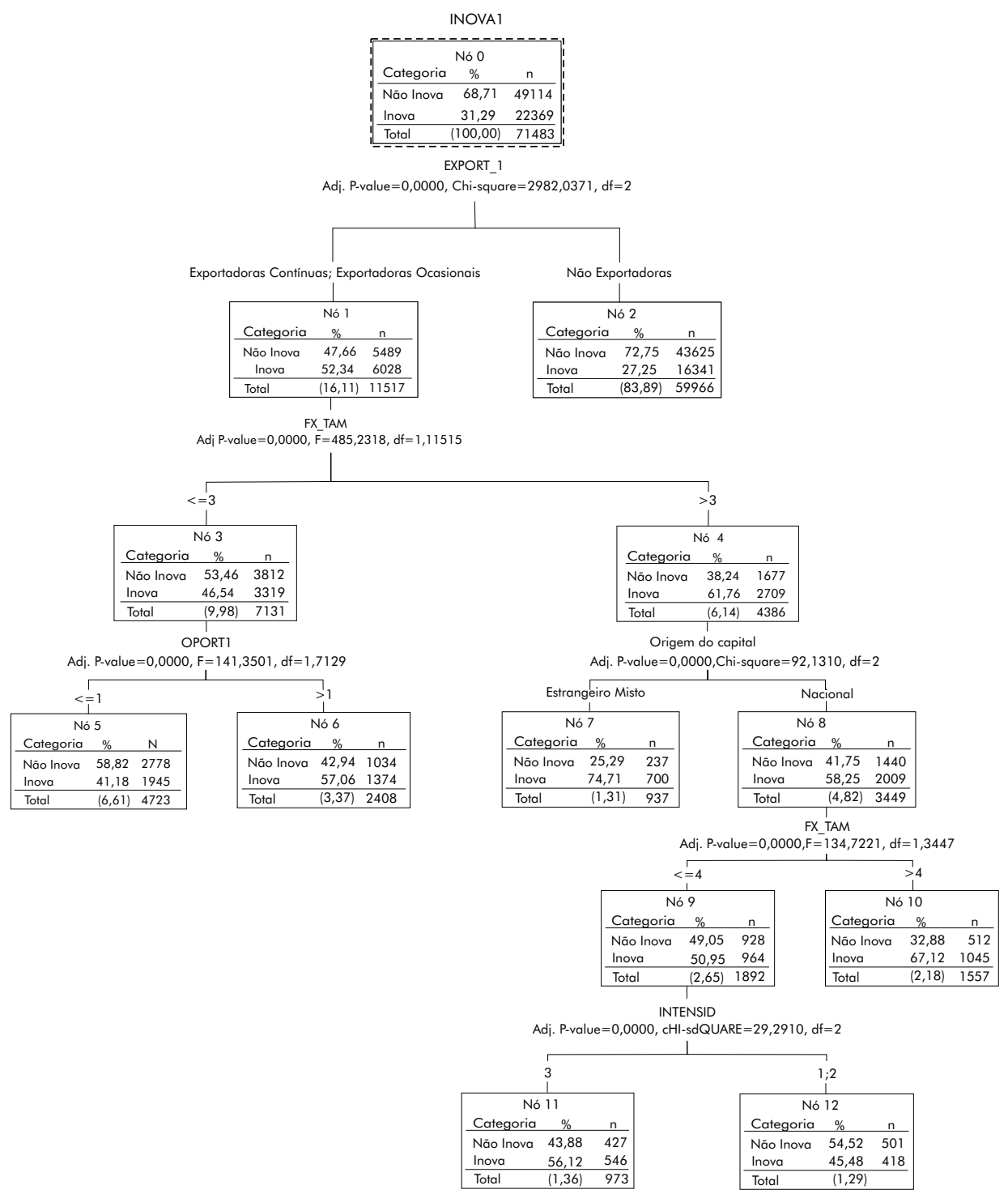

II2 Revista Brasileira de Inovação 
As árvores de classificação 3 e 4 apresentam as estimativas de árvores reduzidas segundo o critério de custo-complexidade quando são estabelecidos custos de má classificação distintos, ajustando-se as probabilidades a priori segundo as variações dos custos. Na Árvore 3 é estabelecido um custo igual a 2 para a classificação errônea de uma empresa inovadora como não-inovadora e custo igual a 1 para classificação errônea de uma empresa não-inovadora como inovadora. Ou seja, na Árvore 3 deve prevalecer a classificação mais acurada da classe de empresas inovadoras. O inverso é feito na Árvore 4. Ou seja, é estabelecido um custo igual a 2 para a classificação errônea de uma empresa nãoinovadora como inovadora e custo igual a 1 para classificação errônea de uma empresa inovadora como não-inovadora. Os sumários estatísticos dessas árvores, apresentados, respectivamente, nas Tabelas 7 e 8, demonstram estas afirmações por meio da observação das matrizes de classificação. Como é possível perceber, o risco da Árvore 3 é aumentado em relação ao risco obtido na Árvore 2, enquanto que o inverso ocorre na Árvore $4 .{ }^{19}$

$\mathrm{Na}$ Árvore 3 é explorado o nó não-inovador da árvore, ou seja, a categoria de empresas não-exportadoras. A informação básica que esta árvore produz é que no caso de empresas não exportadoras, o que importa para a classificação de uma empresa como inovadora é o seu tamanho. Empresas com mais de 100 empregados possuem uma probabilidade maior de serem inovadoras.

TABELA 7

Sumário Estatístico da Árvore de Classificação 2.3 - Custos Assimétricos

\begin{tabular}{ccccccc}
\hline Nós & Freqüência & Percentual & Lucro & & Matriz de Classificação \\
\hline 1 & 11.517 & 18,7 & 0,69 & & Valor Observado \\
4 & 8.208 & 12,3 & 0,58 & Valor Predito & Não Inova & Inova \\
7 & 3.839 & 5,7 & 0,56 & Não Inova & 36.400 & 11.519 \\
8 & 2.675 & 3,6 & 0,43 & & 12.714 & 10.850 \\
5 & 45.244 & 59,7 & 0,38 & Risco & & \\
\end{tabular}

19 Isto ocorre em razão do desequilíbrio das proporções entre empresas inovadoras e não-inovadoras, sendo as últimas aquelas que tem maior proporção de casos na amostra. 
Sérgio Kannebley Junior, Geciane Silveira Porto, Elaine Toldo Pazello

ÁRVORE 3

Custos de Classificação Dobrados para

Má Classificação de Empresas Inovadoras

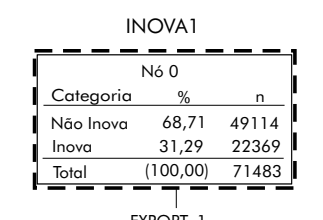

EXPORT 1
Adj. P-value $=0,0000$, Chi-square $=2982,0371, d f=2$

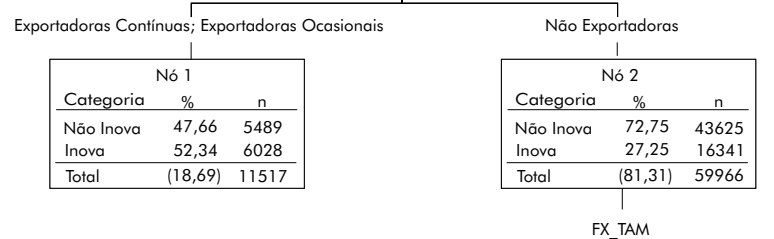

Adj. P-value $=0,0000, F=1035,6662, d f=1,59964$

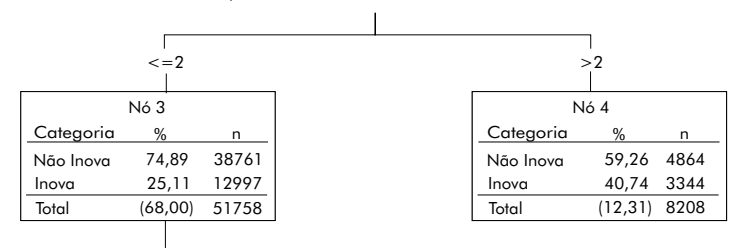

OPORT1

Adi. P-value $=0,0000, F=315,3538, d f=1,51756$

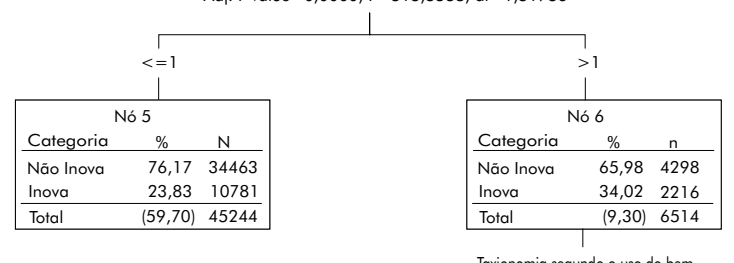

Adj. P-value $=0,0000$, Chi-square $=117,1733, \mathrm{df}=3$

\begin{tabular}{|c|c|c|c|c|c|}
\hline \multicolumn{3}{|c|}{ Bens de capital } & \multirow{2}{*}{\multicolumn{3}{|c|}{$\begin{array}{l}\text { Intermediários; consumo não duravel; } \\
\text { consumo duravel }\end{array}$}} \\
\hline \multicolumn{3}{|c|}{ Nó 7} & \multicolumn{2}{|c|}{ Nó 8} & \\
\hline Categoria & $\%$ & $n$ & Categoria & $\%$ & $\mathrm{~N}$ \\
\hline Não Inova & 61,50 & 2361 & Não Inova & 72,41 & 1937 \\
\hline Inova & 38,50 & 1478 & Inova & 27,59 & 738 \\
\hline Total & $(5,67)$ & 3839 & Total & $(3,64)$ & 2675 \\
\hline
\end{tabular}

II4 Revista Brasileira de Inovação 
ÁRVORE 4

Custos de Classificação Dobrados para

Má Classificação de Empresas Não-Inovadoras

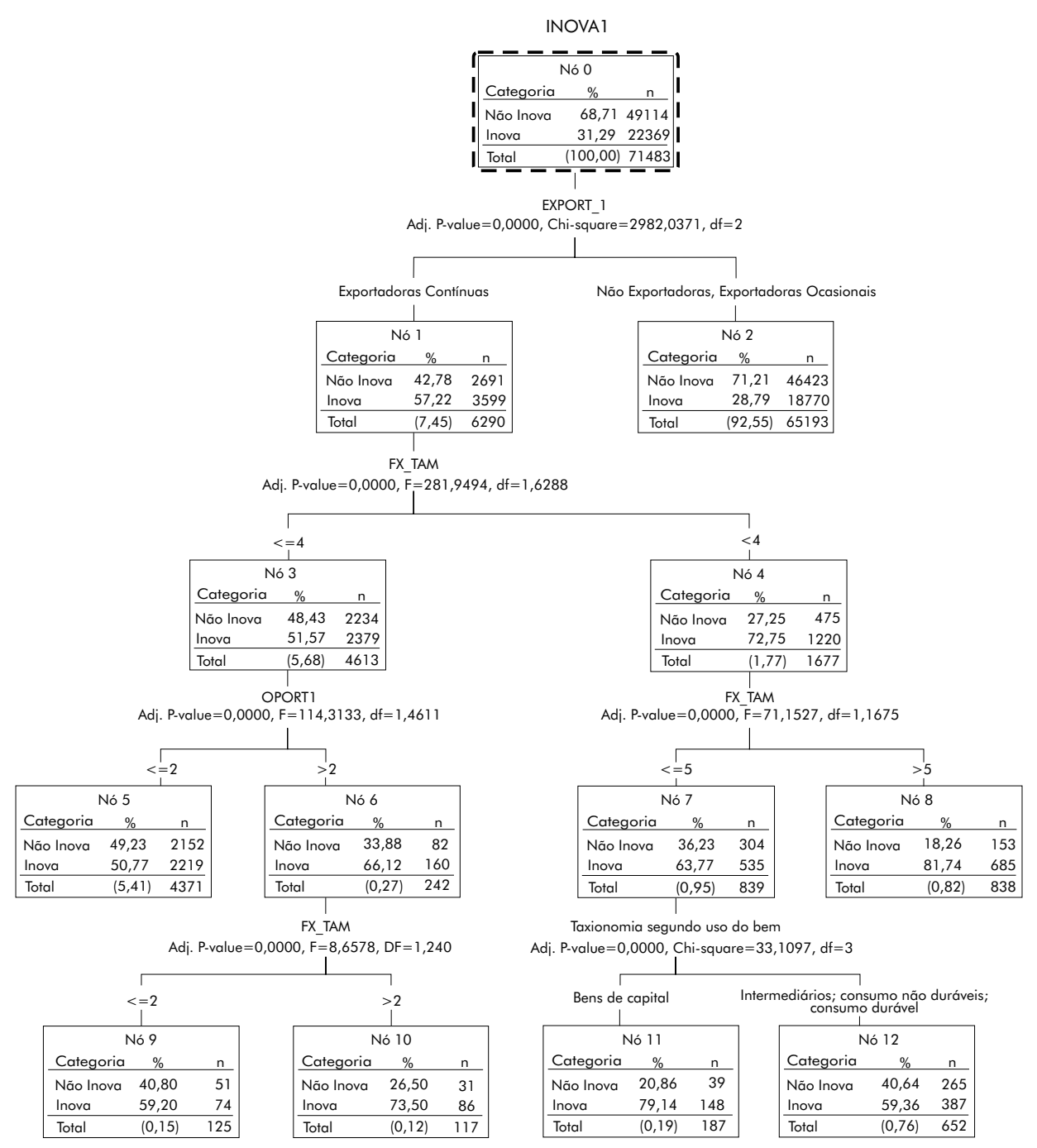


TABELA 8

Sumário Estatístico da Árvore de Classificação 2.4 - Custos Assimétricos

\begin{tabular}{rrrrrrr}
\hline Nós & Freqüência & Percentual & Lucro & \multicolumn{3}{c}{ Matriz de classificação } \\
\hline 8 & 838 & 0,8 & 0,69 & & \multicolumn{2}{c}{ Valor Observado } \\
11 & 187 & 0,2 & 0,65 & $\begin{array}{r}\text { Valor Predito } \\
\text { Não Inova }\end{array}$ & Inova \\
10 & 117 & 0,1 & 0,58 & $\begin{array}{l}\text { Não Inova } \\
\text { Inova }\end{array}$ & 48.891 & 21.450 \\
12 & 652 & 0,8 & 0,42 & & & \\
9 & 125 & 0,1 & 0,42 & Risco & & \\
5 & 4.371 & 5,4 & 0,34 & & & \\
2 & 65.193 & 92,6 & 0,17 & & & \\
\hline
\end{tabular}

Esta informação é corroborada pela classificação produzida pela Árvore 1, em que é estabelecido como um nó inovador as empresas não-exportadoras, com 250 ou mais empregados, pertencentes a setores de média-baixa, média ou alta oportunidade tecnológica.

$\mathrm{Na}$ Árvore 4 é explorado o nó inovador da árvore, ou seja, a classe de empresas exportadoras. Em primeiro lugar destaca-se a importância do caráter contínuo da atividade exportadora, redefinindo o nó inovador inicial. Adicionalmente destaca-se a importância das grandes empresas exportadoras contínuas, com mais de 250 empregados na classificação como empresas inovadoras. O principal nó terminal inovador da árvore informa que $81,74 \%$ das empresas exportadoras contínuas, com 500 ou mais empregados, realizaram inovações no período. Já as empresas exportadoras contínuas, na faixa de 250 e 499 empregados, têm sua probabilidade de ser inovadora bastante aumentada caso pertençam a setores produtores de bens de capital (79,14\%).

\section{Análise setorial - modelos de regressão logística}

Nesta seção são apresentadas as equações setoriais para a probabilidade de inovar. A estimação desses modelos procura complementar a análise para toda indústria realizada anteriormente. Como o intuito de tornar a análise mais focada, 
são discutidos aqui apenas os resultados para os setores em que a taxa de acerto de firmas inovadoras foi superior à média da indústria. Além disso, a análise é centralizada nos resultados do modelo reduzido. Esses setores e as respectivas taxas de acerto de empresas inovadoras e de acerto geral do modelo são apresentados no Quadro 2.

É no setor de Informática, em que 68\% das 158 empresas são inovadoras, que o modelo obtém o maior sucesso em termos da predição das firmas inovadoras: das 108 firmas inovadoras, o modelo classificou acertadamente 107, isto

QUADRO 2

Ranking dos Setores Inovadores

\begin{tabular}{lcc}
\hline Setores & \% de acerto inovadoras & \% geral de acerto \\
\hline Informática & 98,97 & 81,04 \\
Eletrônica Básica & 96,21 & 68,71 \\
Refino de Petróleo & 92,91 & 92,68 \\
Comunicações & 88,59 & 66,43 \\
Médico-Hospitalares & 78,54 & 62,9 \\
Celulose & 71,49 & 80,61 \\
Peças e Acessórios & 63,63 & 71,1 \\
Fumo & 57,76 & 75,9 \\
Farmacêutica & 55,53 & 67,32 \\
Química & 47,75 & 66,95 \\
Máquinas e Equipamentos & 45,29 & 64,59 \\
Siderurgia & 44,29 & 85,24 \\
Materiais Elétricos & 41,17 & 63,38 \\
Reciclagem & 37,84 & 91,08 \\
Bebidas & 35,89 & 72,09 \\
Papel & 31,63 & 79,62 \\
Montagem de Veículos & 27,93 & 79,86 \\
Fabricação de Combustível & 27,05 & 72,14 \\
Têxtil & 27,02 & 69,29 \\
Outros Equipamentos de Transporte & 23,51 & 60,54 \\
Metalurgia & 23,46 & 65,11 \\
Indústria Geral & 22,82 & 70,92 \\
& & \\
& &
\end{tabular}


é, quase 100\%. Nos setores de Eletrônica Básica e de Refino de Petróleo a porcentagem de acerto de firmas inovadoras também é superior a $90 \%$. No primeiro, das 153 firmas inovadoras, o modelo corretamente classifica 147; no segundo, das 17, o modelo corretamente classifica 16. Outros setores que merecem destaque neste item são: Comunicações, Médico-Hospitalares, Celulose, Peças e Acessórios, Fumo e Farmacêutica. Em todos estes, o modelo classificou corretamente mais de $50 \%$ das firmas inovadoras. Um dos fatores que ajudam a explicar o êxito do modelo nestes setores é a alta concentração de firmas inovadoras. No setor de Informática, por exemplo, é onde está o maior percentual de firmas inovadoras. Conforme também pode ser notado no quadro acima, não necessariamente os modelos setoriais que melhor previram as firmas inovadoras serão aqueles que terão as maiores taxas de acerto do modelo como um todo. Isto se deve ao trade-off existente entre os dois tipos de erros característicos deste tipo de exercício. ${ }^{20}$

Nas Tabelas A.2.1, A.2.2 e A.2.3, no Apêndice A.2, são apresentados, respectivamente, os coeficientes, as razões de chance e os efeitos marginais das equações setoriais para a probabilidade de inovar. ${ }^{21}$

Em 18 dos 21 setores que estão sendo destacados, a variável representativa do tamanho da empresa apareceu como uma variável importante para explicar a inovação. Em 17 dessas 18 equações o sinal associado ao seu coeficiente foi positivo, indicando que quanto maior o tamanho, maior a probabilidade da firma inovar. Apenas no caso do setor de Refino de Petróleo tal coeficiente foi negativo. ${ }^{22}$

A origem do capital foi um fator menos relevante setorialmente para explicar a inovação. Em seis dos 21 setores, o coeficiente da variável origem estrangeira foi estatisticamente significativo, sendo que em três setores (Peças e Acessórios, Produtos Químicos e Outros Equipamentos de Transporte) o coeficiente teve sinal positivo, enquanto nos outros três setores (Máquinas e

\footnotetext{
20 Se a inovação caracteriza o setor, o modelo tenderá a classificar mais firmas como inovadoras, diminuindo, de um lado, a probabilidade do erro tipo 1 (classificar como não-inovadora uma firma inovadora) e aumentando a probabilidade do erro tipo 2 (classificar como inovadora uma firma não-inovadora).

${ }^{21} \mathrm{Na}$ Tabela A.2.1 são apresentados o sinal e relevância estatística dos coeficientes. As Tabelas A.2.2 e A.2.3 permitem que se identifique qual foi a variável, ou quais foram as variáveis, com maior poder de explicação da probabilidade de inovar para cada um dos setores.

22 Segundo a PINTEC este setor possui 45 empresas. A maior parte (90\% do total) das empresas é de porte pequeno e médio, sendo a inovação mais freqüente entre as empresas de pequeno porte.
} 
Equipamentos, Material Elétrico e Bebidas) o sinal obtido para o coeficiente foi negativo. Já a variável origem mista do capital, foi significativa em apenas quatro setores (Comunicaçōes, Produtos Farmacêuticos, Produtos Químicos e Têxtil), sendo que somente nos setores de Produtos Químicos e Produtos Têxteis o sinal associado ao coeficiente dessa variável dummy foi positivo.

As variáveis que captam a situação societária da empresa, relativamente às empresas independentes de grupos empresariais, também não foram importantes na determinação da inovação na maior parte destes setores. A variável controladora se mostrou relevante em três setores, sendo que, em um o sinal foi negativo (Peças e Acessórios) e nos outros dois foi positivo (Máquinas e Equipamentos e Têxtil). A variável coligada se mostrou importante em cinco setores: foi negativa para os setores de Peças e Acessórios e Metalurgia e positiva para Farmacêutica, Materiais Elétricos e Bebidas. A variável dummy para a empresa controlada no grupo, por sua vez, foi significativa em um maior número de setores (oito dos 21 que estão sendo focados) e a direção do seu sinal pode ser melhor definida: as controladas apresentam uma menor probabilidade de inovar relativamente às independentes.

Em nove dos 21 um setores, ser exportador ocasional e/ou contínuo aumenta a probabilidade da empresa inovar, comparativamente à empresa nãoexportadora, como esperado pela teoria e em concordância com a análise para a indústria geral. Em apenas quatro setores o sinal foi negativo: Eletrônicos Básicos (variável de exportadora contínua), Fumo (variável de exportadora contínua), Farmacêutico (variável de exportadora ocasional), e Outros Equipamentos de Transporte (variável de exportadora ocasional).

As principais características que determinam tanto positivamente, quanto negativamente, a probabilidade de inovar nas empresas pertencentes a cada um dos setores analisados estão sumarizadas no Quadro 3. É importante notar que a variável representativa do tamanho aparece como aquela que tem o maior efeito marginal sobre a probabilidade de inovar em nove setores industriais, enquanto que as variáveis dummies para a orientação exportadora aparecem com maior efeito marginal e razões de chance também em nove setores, explicando assim a despeito da dominância em termos de significância estatística dos coeficientes, a hierarquização proposta pelas árvores de classificação apresentadas anteriormente. 
Sérgio Kannebley Junior, Geciane Silveira Porto, Elaine Toldo Pazello

QUADRO 3

Sumário dos Resultados — Modelos Logit — Variável Dependente: Inova Geral

\begin{tabular}{|c|c|c|}
\hline Setores & $\begin{array}{l}\text { Principais Determinantes } \\
\text { Positivos da Inovação }\end{array}$ & $\begin{array}{l}\text { Principais Determinantes } \\
\text { Negativos da Inovação }\end{array}$ \\
\hline Informática & Tamanho & \\
\hline Eletrônica Básica & Tamanho & Exportação contínua \\
\hline Refino de Petróleo & $\begin{array}{l}\text { Exportar ocasionalmente / } \\
\text { Exportar continuamente }\end{array}$ & Tamanho \\
\hline Comunicações & $\begin{array}{l}\text { Exportar continuamente / } \\
\text { Ser a controlada no grupo }\end{array}$ & Origem mista do capital \\
\hline Médico-Hospitalares & Tamanho & Ser a controlada no grupo \\
\hline Celulose & $\begin{array}{l}\text { Exportar continuamente }\left({ }^{*}\right) / \\
\text { Exportar ocasionalmente }\left({ }^{*}\right)\end{array}$ & \\
\hline Peças e Acessórios & $\begin{array}{l}\text { Origem estrangeira do capital / exportar } \\
\text { Ocasionalmente / exportar continuamente }\end{array}$ & $\begin{array}{l}\text { Ser a coligada no grupo / } \\
\text { Ser a controladora no grupo }\end{array}$ \\
\hline Fumo & Tamanho & Exportação contínua \\
\hline Farmacêutica & $\begin{array}{l}\text { Ser a coligada no grupo / } \\
\text { Tamanho }\end{array}$ & $\begin{array}{l}\text { Ser a controlada no grupo / } \\
\text { Origem mista do capital }\end{array}$ \\
\hline Química & $\begin{array}{l}\text { Origem mista do capital / } \\
\text { Exportar continuamente }\end{array}$ & Ser a controlada no grupo \\
\hline $\begin{array}{l}\text { Máquinas e } \\
\text { Equipamentos }\end{array}$ & $\begin{array}{l}\text { Ser a controladora no grupo / } \\
\text { Exportar ocasionalmente }\end{array}$ & Origem estrangeira do capital \\
\hline Siderurgia & Tamanho & Exportar ocasionalmente $\left({ }^{*}\right)$ \\
\hline Materiais Elétricos & $\begin{array}{l}\text { Ser a coligada no grupo / } \\
\text { Exportar continuamente }\end{array}$ & Origem estrangeira do capital \\
\hline Reciclagem & Tamanho & Exportar continuamente $(*)$ \\
\hline Bebidas & Ser a coligada no grupo / tamanho & Origem estrangeira do capital \\
\hline Papel & Exportar continuamente / tamanho & \\
\hline Montagem de Veículos & $\begin{array}{l}\text { Exportar ocasionalmente / } \\
\text { Exportar continuamente }\end{array}$ & \\
\hline Fabricação de Combustível & Exportar ocasionalmente & Ser a controlada no grupo \\
\hline Têxtil & $\begin{array}{l}\text { Ser a controladora no grupo / exportar } \\
\text { Continuamente / exportar ocasionalmente }\end{array}$ & $\begin{array}{l}\text { Origem estrangeira do } \\
\text { capital }\left(^{*}\right)\end{array}$ \\
\hline Outros Equip. de Transporte & Origem estrangeira do capital & Exportadora ocasional \\
\hline Metalurgia & Tamanho & $\begin{array}{l}\text { Ser a coligada no grupo / } \\
\text { Ser a controlada no grupo }\end{array}$ \\
\hline Indústria Geral & $\begin{array}{l}\text { Exportar continuamente / tamanho / } \\
\text { Exportar ocasionalmente }\end{array}$ & \\
\hline
\end{tabular}

(*) Coeficientes não significativos estatisticamente em um nível de significância de 10\% segundo estatística de Wald. Possivelmente em razão do pequeno número de empresas, com alguma determinada característica em particular dentro do setor, o coeficiente associado a essa característica não foi estatisticamente significante. No entanto, a mesma variável parece ser relevante na explicação da probabilidade de inovar para as empresas daquele setor já que foi mantida no processo de redução pelos testes de razão de verossimilhança.

I20 Revista Brasileira de Inovação 


\section{Considerações finais}

A PINTEC é uma pesquisa de âmbito nacional para o período de 1998 a 2000 sobre inovação em processo e produto. A unidade de investigação da PINTEC é a empresa industrial, sendo as atividades produtivas industriais classificadas segundo a CNAE. O universo de pesquisa corresponde a 72.005 empresas.

$\mathrm{O}$ artigo centrou-se na análise da inovação em geral. Das 72.005 empresas, 22.697, ou seja, 31,5\% desse total, declararam ter realizado inovações nesse período, independentemente dessas inovações serem apenas inovações para empresa ou para o mercado nacional. Com isso, a análise da variável dependente qualitativa da probabilidade de inovar das empresas se desenvolveu em dois segmentos.

A análise descritiva com todo o conjunto de informaçóes permitiu observar que as empresas não-inovadoras podem ser "estilizadas" como micro ou pequenas, de capital nacional, não-exportadoras e independentes de grupos empresariais. Com relação à empresa inovadora esta estilização não é tão simples de ser realizada. Conforme ficou evidenciado posteriormente pela análise setorial, todas as variáveis consideradas são importantes na definição das características das empresas inovadoras, mas em muitos casos esta definição depende da interação entre as características consideradas em conjunção com os efeitos setoriais.

A estimativa do modelo de regressão logística para toda a indústria apontou a posição proeminente da característica de exportadora contínua das empresas como a que mais contribui para um aumento na probabilidade de uma empresa ser inovadora. $\mathrm{O}$ tamanho e o caráter ocasional da exportação são características que também merecem destaque na definição da probabilidade da empresa ser inovadora, ainda que todas as demais características de origem estrangeira ou mista do capital e de pertencerem a grupo empresarial, quando tomadas com relação à característica referencial (nacional e independente), tenham sido importantes na definição da probabilidade de inovar da empresa.

As árvores de regressão e classificação, além de confirmarem o ordenamento das características proposto pelos modelos de regressão logística, demonstraram a importância das diferentes formas de interação entre as características das empresas e as classificações setoriais para a determinação da probabilidade de inovar da empresa. As três principais interações apresentadas pelas árvores são: i) as de empresas exportadoras, com 100 ou mais empregados e de capital estrangeiro ou 
misto; ii) empresas exportadoras, com 250 ou mais empregados e de capital nacional; e iii) empresas exportadoras, com 30 ou mais e menos de 100 empregados pertencentes a setores de média-baixa, média e alta oportunidades tecnológicas. As árvores ainda demonstraram que para as empresas não-exportadoras, duas características são importantes na definição da probabilidade de ser inovadora. A primeira é o tamanho e a segunda é a classificação setorial oferecida pelos setores produtores de bens de capital.

Setorialmente, ainda que estes resultados não possam ser extrapolados diretamente, algumas associações são possíveis conforme demonstrado pelas estimaçôes dos modelos de regressão logística. Em primeiro lugar, é possível notar que o fato de ser significativa a variável de tamanho e de ter ela um impacto positivo sobre a probabilidade de inovar pelos modelos setoriais, isso é compatível com a análise para a indústria geral, já que, segundo os resultados do modelo de regressão logística e das árvores de classificação, a variável de tamanho contribui positivamente em determinar a probabilidade de inovar para as empresas tanto exportadoras como não-exportadoras. Com relação à orientação exportadora é importante notar que dos 21 setores para os quais foi possível realizar inferências minimamente confiáveis a partir dos modelos logit, os coeficientes relacionados à orientação exportadora foram os que mais se demonstraram estatisticamente significantes depois da variável de tamanho. Ainda é importante notar que, dos 21 modelos estimados, a orientação exportadora apresentou efeitos marginais superiores aos da variável de tamanho em nove equações setoriais, o que ajuda a explicar a primeira posição em termos de poder explicativo apresentada na análise para a indústria geral.

Uma variável da qual se esperava maior contribuição à probabilidade era a origem estrangeira ou mista do capital, o que não foi observado nas análises realizadas. Isto não significa propriamente que a contribuição à atividade inovativa do capital misto ou estrangeiro seja pouco relevante na indústria brasileira. O que estes resultados refletem é que o volume de inovações das empresas com essa característica tem pouco poder contributivo no total das inovações conduzidas na indústria no período. No entanto, quando são observados outros resultados, não apresentados aqui, relacionados à diferenciação entre inovações apenas para a empresa e inovações para o mercado, a característica estrangeira ou mista do capital ganha maior relevância. 


\section{Bibliografia}

Andreassi, T.; Sbragia, R., "Fatores Determinantes do Grau de Novatividade das Empresas: um Estudo Utilizando a Técnica de Análise Discriminante", in Série de working papers da FEAUSP. No. 001/004. www.ead.fea.usp.br/wpapers, 2002.

Breiman, L.; Friedman, J. H.; Olsen, R. A., Classification and Regression Trees, Belmont, CA: Wadsworth, 358 p., 1984.

Cohen, W. M., "Empirical Studies of Innovative Activity", in Stoneman, P. (org.), Handbook of the economics of innovation and technological change. Oxford: Blackwell, 1995.

; Levin, R. C., "Empirical Studies of Innovative Activity and Market structure", in Schmalensee, R.; Willig, R. (orgs.), Handbook of Industrial Organization, Amsterdã: North Holland, 1989.

Gnanadesikan, R., Methods for Statistical Data Analyisis of Multivariate Observations, Nova York: John Wiley \& Sons, Inc, 1977.

Kannebley, S. Jr., "Características das Firmas Inovadoras no Estado de São Paulo: Uma Análise Empírica a partir da PAEP” ,Texto para Discussão FEA-RP/USP, Série Economia, n.402003.

Kass, G. V., "An Exploratory Technique for Investigating Large Quantities of Categorical Data”, in Applied Statistics. Royal Statistical Society, 29 (2): 119-127, 1980.

Kumar, N.; Siddharthan, N. S., "Technology, Market Structure and Internalization: Issues and Policies for Developing Countries”, Londres: Routledge, 1997.

Loh, W. Y.; Shih, Y. S., "Split Selection Methods for Classification Tress", in Statistica Sinica, 7: 815-840, 1997.

Macedo, P. B. R.; Albuquerque, E. M., "P\&D e Tamanho da Empresa: Evidência Empírica Sobre a Indústria Brasileira”, in Revista Estudos Econômicos, v.29, n.3. p.343-365, 1999.

Moreira, M. M.; Najberg, S., "Abertura Comercial: Criando ou Destruindo Empregos?”, in Pesquisa e Planejamento Econômico, IPEA, 28 (2): ago., 1998.

Quadros, R.; Furtado, A.; Bernardes, R.; Franco, E., “Technological Innovation in Brazilian Industry: an Assessment Based on the São Paulo Innovation Survey", in Technological Forecasting and Social Change, 67 (2-3): 203-219, jun., 2001.

Sbragia, R.; Krugliankas, I; Arango-Alzare, T., "Empresas Inovadoras no Brasil: uma Proposição de Tipologia e Características Associadas", in Série Working Papers FEA/USP No. 001/003. www.ead.fea.usp.br/wpapers, 2002. 
Apêndice A.1.

Classificação Setorial Segundo a Oportunidade Tecnológica

\section{Baixa Oportunidade}

Indústrias extrativas

Fabricação de produtos alimentícios

Fabricação de bebidas

Fabricação de produtos do fumo

Fabricação de produtos têxteis

Confecção de artigos do vestuário e acessórios

Preparação de couros e fabricação de artefatos de couro, artigos de viagem e calçados

Fabricação de celulose e outras pastas

Fabricação de papel, embalagens e artefatos de papel

Edição, impressão e reprodução de gravações

Fabricação de coque, refino de petróleo, elaboração de combustíveis nucleares e produção de álcool

Fabricação de coque, álcool e elaboração de combustíveis nucleares

Fabricação de artigos de borracha e plástico

Fabricação de produtos de minerais não-metálicos

Metalurgia básica - exclusive produtos siderúrgicos

Fabricação de peças e acessórios para veículos automotores

Fabricação de artigos do mobiliário

Fabricação de produtos diversos

Reciclagem

Média-baixa Oportunidade

Metalurgia de metais não-ferrosos e fundição

Refino do petróleo

Fabricação de produtos químicos

Fabricação de produtos farmacêuticos

Produtos siderúrgicos

Fabricação de máquinas e equipamentos

Fabricação de material eletrônico básico

I24 Revista Brasileira de Inovação 


\section{Média Oportunidade}

Fabricação de aparelhos e equipamentos de comunicação - exclusive fabricação de material eletrônico básico

Fabricação de equipamentos de instrumentação médico-hospitalares, instrumentos de precisão e ópticos, equipamentos para automação industrial, cronômetros e relógios

Fabricação e montagem de veículos automotores, reboques e carrocerias exclusive fabricação de peças e acessórios para veículos

Alta Oportunidade

Fabricação de máquinas para escritório e equipamentos de informática Fabricação de outros equipamentos de transporte 


\section{Apêndice A.2.}

\section{Resultados dos Modelos de Regressão Logística}

TABELA A.2.1

Impacto das Características das Empresas sobre a Probabilidade da Empresa Ser Inovadora - Setores Industriais - Modelo Reduzido

\begin{tabular}{|c|c|c|c|c|c|c|c|c|c|}
\hline \multicolumn{10}{|c|}{ variável dependente $=$ probabilidade da empresa ser inovadora } \\
\hline \multirow{2}{*}{$\begin{array}{l}\text { Variáveis } \\
\text { Explicativas } \\
\text { Setores } \\
\text { Industriais }\end{array}$} & \multirow{2}{*}{ Constante } & \multirow{2}{*}{$\begin{array}{c}\text { Emprego } \\
\text { Ln } \\
\text { Emprego }\end{array}$} & \multicolumn{2}{|c|}{$\begin{array}{l}\text { Origem do Capital } \\
\text { Referência=Nacional }\end{array}$} & \multicolumn{3}{|c|}{$\begin{array}{l}\text { Situação da Empresa } \\
\text { Referência=Independente }\end{array}$} & \multicolumn{2}{|c|}{$\begin{array}{c}\text { Exportadora } \\
\text { Referência }=\text { Não Exporta }\end{array}$} \\
\hline & & & Estrangeiro & Misto & Controladorc & Controlado & Coligada & $\begin{array}{l}\text { Ocasional- } \\
\text { mente }\end{array}$ & $\begin{array}{c}\text { Continua- } \\
\text { mente }\end{array}$ \\
\hline Informática & $\begin{array}{r}-1,973 \\
(7,505)\end{array}$ & $\begin{array}{c}0,728 \\
(14,200)\end{array}$ & & & & & & & \\
\hline $\begin{array}{l}\text { Eletrônicos } \\
\text { Básicos }\end{array}$ & $\begin{array}{l}-0,668 \\
(1,946)\end{array}$ & $\begin{array}{l}0,415 \\
(7,284)\end{array}$ & & & & & & $\begin{array}{c}0,694 \\
(1,763)\end{array}$ & $\begin{array}{l}-1,293 \\
(9,360)\end{array}$ \\
\hline $\begin{array}{l}\text { Refino de } \\
\text { Petróleo }\end{array}$ & $\begin{array}{l}-3,058 \\
(0,001)\end{array}$ & $\begin{array}{l}-2,637 \\
(4,272)\end{array}$ & $\begin{array}{c}-15,023 \\
(0,011)\end{array}$ & $\begin{array}{l}31,266 \\
(0,005)\end{array}$ & $\begin{array}{l}10,620 \\
(0,001)\end{array}$ & $\begin{array}{l}17,791 \\
(0,040)\end{array}$ & $\begin{array}{l}30,948 \\
(0,005)\end{array}$ & $\begin{array}{l}39,660 \\
(0,008)\end{array}$ & $\begin{array}{l}32,302 \\
(0,036)\end{array}$ \\
\hline Comunicações & $\begin{array}{l}0,177 \\
(1,238)\end{array}$ & & $\begin{array}{l}7,695 \\
(0,175)\end{array}$ & $\begin{array}{l}-1,671 \\
(3,248)\end{array}$ & $\begin{array}{l}8,475 \\
(0,044)\end{array}$ & $\begin{array}{c}1,291 \\
(5,695)\end{array}$ & $\begin{array}{r}9,599 \\
(0,120)\end{array}$ & $\begin{array}{l}-0,422 \\
(1,742)\end{array}$ & $\begin{array}{r}1,435 \\
(6,281)\end{array}$ \\
\hline $\begin{array}{l}\text { Médico- } \\
\text { Hospitalares }\end{array}$ & $\begin{array}{l}-1,558 \\
(21,207)\end{array}$ & $\begin{array}{c}0,527 \\
(30,592)\end{array}$ & & & $\begin{array}{l}-1,254 \\
(1,550)\end{array}$ & $\begin{array}{r}-0,779 \\
(4,098)\end{array}$ & $\begin{array}{r}7,994 \\
(0,686)\end{array}$ & & \\
\hline Celulose & $\begin{array}{l}-1,083 \\
(2,794)\end{array}$ & & & & & & & $\begin{array}{c}1,083 \\
(0,485)\end{array}$ & $\begin{array}{l}11,286 \\
(0,033)\end{array}$ \\
\hline $\begin{array}{l}\text { Peças e } \\
\text { Acessórios }\end{array}$ & $\begin{array}{c}-1,622 \\
(31,736)\end{array}$ & $\begin{array}{c}0,232 \\
(7,518)\end{array}$ & $\begin{array}{c}1,309 \\
(15,201)\end{array}$ & $\begin{array}{c}6,209 \\
(0,933)\end{array}$ & $\begin{array}{l}-1,342 \\
(2,773)\end{array}$ & $\begin{array}{c}0,157 \\
(0,099)\end{array}$ & $\begin{array}{r}-3,161 \\
(16,807)\end{array}$ & $\begin{array}{c}1,135 \\
(16,452)\end{array}$ & $\begin{array}{c}1,045 \\
(23,778)\end{array}$ \\
\hline Fumo & $\begin{array}{l}-5.599 \\
(8.096)\end{array}$ & $\begin{array}{l}1.343 \\
(8.396)\end{array}$ & & & & & & $\begin{array}{l}-8.418 \\
(0.073)\end{array}$ & $\begin{array}{l}-2.811 \\
(5.683)\end{array}$ \\
\hline Farmacêutico & $\begin{array}{c}-3,036 \\
(58,021)\end{array}$ & $\begin{array}{c}0,726 \\
(45,633)\end{array}$ & $\begin{array}{c}0,507 \\
(1,086)\end{array}$ & $\begin{array}{l}-1,197 \\
(3,133)\end{array}$ & $\begin{array}{l}-1,041 \\
(1,379)\end{array}$ & $\begin{array}{l}-1,716 \\
(9,338)\end{array}$ & $\begin{array}{r}1,867 \\
(5,754)\end{array}$ & $\begin{array}{l}-0,655 \\
(3,060)\end{array}$ & $\begin{array}{l}0,457 \\
(2,389)\end{array}$ \\
\hline Química & $\begin{array}{c}-1,909 \\
(124,230)\end{array}$ & $\begin{array}{c}0,401 \\
(64,536)\end{array}$ & $\begin{array}{c}0,480 \\
(7,588)\end{array}$ & $\begin{array}{c}1,790 \\
(13,264)\end{array}$ & $\begin{array}{l}0,667 \\
(1,280)\end{array}$ & $\begin{array}{c}-0,650 \\
(11,195)\end{array}$ & $\begin{array}{r}0,203 \\
(0,187)\end{array}$ & $\begin{array}{l}0,205 \\
(2,200)\end{array}$ & $\begin{array}{c}1,170 \\
(81,260)\end{array}$ \\
\hline $\begin{array}{l}\text { Máquinas e } \\
\text { Equipamentos }\end{array}$ & $\begin{array}{c}-2,330 \\
(283,161)\end{array}$ & $\begin{array}{c}0,535 \\
(163,223)\end{array}$ & $\begin{array}{l}-0,348 \\
(5,027)\end{array}$ & $\begin{array}{l}0,350 \\
(1,161)\end{array}$ & $\begin{array}{l}2,057 \\
(6,541)\end{array}$ & $\begin{array}{c}0,138 \\
(0,539)\end{array}$ & $\begin{array}{l}-0,445 \\
(0,969)\end{array}$ & $\begin{array}{c}0,841 \\
(72,393)\end{array}$ & $\begin{array}{c}0,604 \\
(40,311)\end{array}$ \\
\hline Siderurgia & $\begin{array}{c}-4,524 \\
(64,643)\end{array}$ & $\begin{array}{c}0,680 \\
(21,124)\end{array}$ & & & & & & $\begin{array}{l}-0,573 \\
(0,967)\end{array}$ & $\begin{array}{l}0,710 \\
(2,517)\end{array}$ \\
\hline $\begin{array}{l}\text { Materiais } \\
\text { Elétricos }\end{array}$ & $\begin{array}{c}-0,360 \\
(31,477)\end{array}$ & & $\begin{array}{c}-0,781 \\
(10,943)\end{array}$ & $\begin{array}{l}-0,001 \\
(0,000)\end{array}$ & $\begin{array}{l}0,356 \\
(0,178)\end{array}$ & $\begin{array}{c}0,952 \\
(11,046)\end{array}$ & $\begin{array}{r}2,250 \\
(4,826)\end{array}$ & $\begin{array}{c}0,687 \\
(16,548)\end{array}$ & $\begin{array}{c}1,333 \\
(57,791)\end{array}$ \\
\hline Reciclagem & $\begin{array}{c}-8,117 \\
(16,932)\end{array}$ & $\begin{array}{c}1,842 \\
(9,828)\end{array}$ & & & & $\begin{array}{l}10,766 \\
(0,075)\end{array}$ & & $\begin{array}{l}-1,123 \\
(0,421)\end{array}$ & $\begin{array}{c}-21,018 \\
(0,038)\end{array}$ \\
\hline Bebidas & $\begin{array}{c}-3.931 \\
(124.599)\end{array}$ & $\begin{array}{c}0.835 \\
(84.010)\end{array}$ & $\begin{array}{c}-2.085 \\
(14.349)\end{array}$ & $\begin{array}{l}-1.849 \\
(1.725)\end{array}$ & $\begin{array}{l}-0.788 \\
(1.059)\end{array}$ & $\begin{array}{l}-0.661 \\
(2.733)\end{array}$ & $\begin{array}{r}2.830 \\
(32.095)\end{array}$ & & \\
\hline Papel & $\begin{array}{c}-4,076 \\
(173,108)\end{array}$ & $\begin{array}{c}0,729 \\
(78,527)\end{array}$ & & & & & & $\begin{array}{c}0,129 \\
(0,287)\end{array}$ & $\begin{array}{c}1,034 \\
(13,151)\end{array}$ \\
\hline $\begin{array}{l}\text { Montagem } \\
\text { de Veículos }\end{array}$ & $\begin{array}{c}-3,562 \\
(58,394)\end{array}$ & $\begin{array}{c}0,721 \\
(24,654)\end{array}$ & & & & & & $\begin{array}{c}1,813 \\
(11,642)\end{array}$ & $\begin{array}{c}1,651 \\
(5,788)\end{array}$ \\
\hline $\begin{array}{l}\text { Fabricação de } \\
\text { combustíveis }\end{array}$ & $\begin{array}{c}-4,409 \\
(14,108)\end{array}$ & $\begin{array}{l}0,643 \\
(9,153)\end{array}$ & $\begin{array}{l}-7,164 \\
(0,087)\end{array}$ & $\begin{array}{l}0,638 \\
(2,751)\end{array}$ & $\begin{array}{l}8,073 \\
(0,067)\end{array}$ & $\begin{array}{l}-1,907 \\
(4,630)\end{array}$ & $\begin{array}{l}-0,353 \\
(0,136)\end{array}$ & $\begin{array}{c}1,149 \\
(5,373)\end{array}$ & $\begin{array}{c}0,174 \\
(0,108)\end{array}$ \\
\hline Têxtil & $\begin{array}{c}-1,639 \\
(106,850)\end{array}$ & $\begin{array}{c}0,147 \\
(10,606)\end{array}$ & $\begin{array}{l}-0,541 \\
(2,413)\end{array}$ & $\begin{array}{c}4,362 \\
(0,105)\end{array}$ & $\begin{array}{c}3,281 \\
(33,243)\end{array}$ & $\begin{array}{c}0,342 \\
(1,300)\end{array}$ & $\begin{array}{l}-0,060 \\
(0,014)\end{array}$ & $\begin{array}{c}0,945 \\
(42,061)\end{array}$ & $\begin{array}{c}1,218 \\
(87,974)\end{array}$ \\
\hline $\begin{array}{l}\text { Outros Equip. } \\
\text { de Transporte }\end{array}$ & $\begin{array}{l}-1,038 \\
(6,952)\end{array}$ & $\begin{array}{c}0,227 \\
(3,579)\end{array}$ & $\begin{array}{c}1,483 \\
(4,983)\end{array}$ & & & & & $\begin{array}{l}-0,874 \\
(4,875)\end{array}$ & $\begin{array}{c}0,317 \\
(0,459)\end{array}$ \\
\hline Metalurgia & $\begin{array}{c}-3,018 \\
(69,722)\end{array}$ & $\begin{array}{c}0,783 \\
(43,160)\end{array}$ & & & $\begin{array}{l}-2,442 \\
(1,332)\end{array}$ & $\begin{array}{c}-2,136 \\
(12,566)\end{array}$ & $\begin{array}{l}-2,661 \\
(3,100)\end{array}$ & $\begin{array}{l}-0,425 \\
(1,418)\end{array}$ & $\begin{array}{c}0,493 \\
(2,771)\end{array}$ \\
\hline
\end{tabular}

I26 Revista Brasileira de Inovação 
Inovação na Indústria Brasileira: uma Análise Exploratória a Partir da PINTEC

TABELA A.2.2

Razões de Chance das Características das Empresas sobre a Probabilidade da Empresa ser Inovadora - Setores Industriais*

\begin{tabular}{|c|c|c|c|c|c|c|c|c|}
\hline \multicolumn{9}{|c|}{ variável dependente $=$ probabilidade da empresa ser inovadora } \\
\hline \multirow{2}{*}{$\begin{array}{l}\text { Variáveis Explicativas } \\
\text { Setores Industriais }\end{array}$} & \multirow{2}{*}{$\begin{array}{l}\text { Emprego } \\
\text { Ln } \\
\text { Emprego }\end{array}$} & \multicolumn{2}{|c|}{$\begin{array}{l}\text { Origem do Capital } \\
\text { Referência=Nacional }\end{array}$} & \multicolumn{3}{|c|}{$\begin{array}{l}\text { Situação da Empresa } \\
\text { Referência=Independente }\end{array}$} & \multicolumn{2}{|c|}{$\begin{array}{c}\text { Exportadora } \\
\text { Referência }=\text { Não Exporta }\end{array}$} \\
\hline & & Estrangeiro & Misto & Controladora & Controlada & Coligada & $\begin{array}{l}\text { Ocasional- } \\
\text { mente }\end{array}$ & $\begin{array}{l}\text { Continua- } \\
\text { mente }\end{array}$ \\
\hline Informática & $2,071^{* *}$ & & & & & & & \\
\hline Eletrônicos Básicos & $1,514^{* *}$ & & & & & & 2,001 & $0,274^{* *}$ \\
\hline Refino de Petróleo & $0,072^{* *}$ & 0,000 & $3,79 E+13$ & $4,10 E+04$ & $5,33 \mathrm{E}+07$ & $2,76 E+13$ & $1,68 \mathrm{E}+17$ & $1,07 E+14$ \\
\hline Comunicações & & $2,20 E+03$ & $0,188^{* *}$ & $4,79 E+03$ & $3,635^{* *}$ & $1,48 \mathrm{E}+04$ & 0,656 & $4,198^{* *}$ \\
\hline Médico-Hospitalares & $1,694^{* *}$ & & & 0,285 & $0,459^{* *}$ & $2,96 \mathrm{E}+03$ & & \\
\hline Celulose & & & & & & & 2,953 & $7,97 E+04$ \\
\hline Peças e Acessórios & $1,261^{* *}$ & $3,703^{* *}$ & 496,992 & $0,261^{* *}$ & 1,170 & $0,042^{* *}$ & $3,112^{* *}$ & $2,844^{* *}$ \\
\hline Fumo & $3,832^{* *}$ & & & & & & 0,000 & $0,060^{* *}$ \\
\hline Farmacêutico & $2,067^{* *}$ & 1,661 & $0,302^{* *}$ & 0,353 & $0,180^{* *}$ & $6,471^{* *}$ & $0,519^{* *}$ & 1,579 \\
\hline Química & $1,493^{* *}$ & $1,616^{* *}$ & $5,987^{* *}$ & 1,949 & $0,522^{* *}$ & 1,224 & 1,228 & $3,223^{* *}$ \\
\hline $\begin{array}{l}\text { Máquinas e } \\
\text { Equipamentos }\end{array}$ & $1,707^{* *}$ & $0,706^{* *}$ & 1,419 & $7,826^{* *}$ & 1,148 & 0,641 & $2,319^{* *}$ & $1,830^{* *}$ \\
\hline Siderurgia & $1,974^{* *}$ & & & & & & 0,564 & 2,034 \\
\hline Materiais Elétricos & & 0,458 & $0,999^{* *}$ & $1,428^{* *}$ & 2,590 & 9,491 & 1,987 & 3,792 \\
\hline Reciclagem & $3,057^{* *}$ & & & & 4,944 & & 3,179 & 0,796 \\
\hline Bebidas & $2,305^{* *}$ & $0,124^{* *}$ & 0,157 & 0,455 & $0,516^{* *}$ & $16,943^{* *}$ & & \\
\hline Papel & $2,074^{* *}$ & & & & & & 1,138 & $2,813^{* *}$ \\
\hline $\begin{array}{l}\text { Montagem de } \\
\text { Veículos }\end{array}$ & $2,057^{* *}$ & & & & & & $6,132^{* *}$ & $5,213^{* *}$ \\
\hline $\begin{array}{l}\text { Fabricação de } \\
\text { combustíveis }\end{array}$ & $1,902^{* *}$ & 0,001 & & 3206,151 & $0,149^{* *}$ & 0,702 & $3,155^{* *}$ & 1,190 \\
\hline Têxtil & $1,159^{* *}$ & 0,582 & $1,893^{* *}$ & $26,600^{* *}$ & 1,408 & 0,941 & $2,573^{* *}$ & $3,381^{* *}$ \\
\hline $\begin{array}{l}\text { Outros Equip. } \\
\text { de Transporte }\end{array}$ & $1,255^{* *}$ & $4,407^{* *}$ & 78,405 & & & & $0,417^{* *}$ & 1,373 \\
\hline Metalurgia & $2,189^{* *}$ & & & 0,087 & $0,118^{* *}$ & $0,070^{* *}$ & 0,654 & $1,638^{* *}$ \\
\hline
\end{tabular}

* Modelo Reduzido. " Estatisticamente significativos com 10\% de confiança, no máximo. 
Sérgio Kannebley Junior, Geciane Silveira Porto, Elaine Toldo Pazello

TABELA A.2.3

Efeito Marginal das Características das Empresas sobre a

Probabilidade da Empresa ser Inovadora - Setores Industriais**

\begin{tabular}{|c|c|c|c|c|c|c|c|c|}
\hline \multirow{3}{*}{$\begin{array}{l}\text { Variáveis Explicativas } \\
\text { Setores Industriais }\end{array}$} & \multicolumn{8}{|c|}{ variável dependente $=$ probabilidade da empresa ser inovadora } \\
\hline & \multirow{2}{*}{$\begin{array}{c}\text { Emprego } \\
\text { Ln } \\
\text { Emprego }\end{array}$} & \multicolumn{2}{|c|}{$\begin{array}{l}\text { Origem do Capital } \\
\text { Referência= = Nacional }\end{array}$} & \multicolumn{3}{|c|}{$\begin{array}{l}\text { Situação da Empresa } \\
\text { Referência = Independente }\end{array}$} & \multicolumn{2}{|c|}{$\begin{array}{c}\text { Exportadora } \\
\text { Referência=Não Exporto }\end{array}$} \\
\hline & & Estrangeiro & Misto & Controladora & Controlada & Coligada & $\begin{array}{l}\text { Ocasional- } \\
\text { mente }\end{array}$ & $\begin{array}{l}\text { Continua- } \\
\text { mente }\end{array}$ \\
\hline Informática & $0,149^{* *}$ & & & & & & & \\
\hline Eletrônicos Básicos & $0,096^{* *}$ & & & & & & 0,160 & $-0,298^{* *}$ \\
\hline Refino de Petróleo & $-0,084^{* *}$ & $-0,478$ & 0,994 & 0,338 & 0,566 & 0,984 & 1,261 & 1,027 \\
\hline Comunicações & & 1,105 & $-0,240^{* *}$ & $\begin{array}{c}1,217 \\
-\end{array}$ & $0,185^{* *}$ & 1,378 & $-0,061$ & $0,206^{* *}$ \\
\hline Médico-Hospitalares & $0,116^{* *}$ & & & 0,276 & $-0,172^{* *}$ & 1,761 & & \\
\hline Celulose & & & & & & & 0,065 & 0,682 \\
\hline Peças e Acessórios & $0,058^{* *}$ & $0,326^{* *}$ & 1,547 & $-0,334^{* *}$ & 0,039 & $-0,788^{* *}$ & $0,283^{* *}$ & $0,260^{* *}$ \\
\hline Fumo & $0,193^{* *}$ & & & & & & $-1,209$ & $-0,404^{* *}$ \\
\hline Farmacêutico & $0,181^{* *}$ & 0,127 & $-0,299 * *$ & $-0,260$ & $-0,428^{* *}$ & $0,466^{* *}$ & $-0,164^{* *}$ & 0,114 \\
\hline Química & $0,100^{* *}$ & $0,119^{* *}$ & $0,445^{* *}$ & 0,166 & $-0,162^{* *}$ & 0,050 & 0,051 & $0,291^{* *}$ \\
\hline $\begin{array}{l}\text { Máquinas e } \\
\text { Equipamentos }\end{array}$ & $0,132^{* *}$ & $0,086^{* *}$ & 0,086 & $0,508^{* *}$ & 0,034 & $-0,110$ & $0,208^{* *}$ & $0,149^{* *}$ \\
\hline Siderurgia & $0,084^{* *}$ & & & & & & $-0,071$ & 0,088 \\
\hline Materiais Elétricos & & $-0,195^{* *}$ & 0,000 & 0,089 & $0,238^{* *}$ & $0,562^{* *}$ & $0,172^{* *}$ & $0,333^{* *}$ \\
\hline Reciclagem & $0,171^{* *}$ & & & & 1,000 & & $-0,104$ & $-1,952$ \\
\hline Bebidas & $0,179^{* *}$ & $-0,447^{* *}$ & $-0,397$ & $-0,169$ & $-0,142^{* *}$ & $0,607^{* *}$ & & \\
\hline Papel & $0,122^{* *}$ & & & & & & 0,022 & $0,173^{* *}$ \\
\hline $\begin{array}{l}\text { Montagem de } \\
\text { Veículos }\end{array}$ & $0,137^{* *}$ & & & & & & $0,344^{* *}$ & $0,314^{* *}$ \\
\hline $\begin{array}{l}\text { Fabricação de } \\
\text { combustíveis }\end{array}$ & $0,136^{* *}$ & $-1,516$ & & 1,708 & $-0,404^{* *}$ & $-0,075$ & $0,243^{* *}$ & 0,037 \\
\hline Têxtil & $0,032^{* *}$ & $-0,116$ & $0,137^{* *}$ & $0,702^{* *}$ & 0,073 & $-0,013$ & $0,202^{* *}$ & $0,261^{* *}$ \\
\hline $\begin{array}{l}\text { Outros Equip. } \\
\text { de Transporte }\end{array}$ & $0,056^{* *}$ & $0,366^{* *}$ & 1,075 & & & & $-0,215^{* *}$ & 0,078 \\
\hline Metalurgia & $0,180^{* *}$ & & & $-0,561$ & $-0,490^{* *}$ & $-0,611^{* *}$ & $-0,098$ & $0,113^{* *}$ \\
\hline
\end{tabular}

* Modelo Reduzido. "Estatisticamente significativos com 10\% de confiança, no máximo.

I28 Revista Brasileira de Inovação 